\title{
The Mechanism of Nucleocytoplasmic Transport through the Nuclear Pore Complex
}

\author{
J. Tetenbaum-Novatt And M.P. Rout \\ Laboratory of Cellular and Structural Biology, The Rockefeller University, New York, New York 10065 \\ Correspondence: rout@rockefeller.edu
}

\begin{abstract}
The nuclear pore complex (NPC) mediates all transport between the nucleus and cytoplasm. Passage through the NPC is highly selective, yet the same channel must allow rapid specific transport of a wide range of cargoes. This chapter focuses mainly on the phenylalanine-glycine (FG) nucleoporins (nups), proteins carrying natively unfolded regions that are thought to form the selectively permeable barrier within the NPC. The physical properties of the FG nup barrier remain unclear. The high selectivity and rapidity of transport observed in vivo may be explained, in part, by competition for binding and space between transport factors and nontransported proteins. Future studies of FG nups will therefore also examine their interactions between FG nups and other proteins in their surroundings.
\end{abstract}

Unlike their prokaryotic ancestors, eukaryotic cells contain numerous membrane-bound organelles that compartmentalize various specialized processes. This evolutionary advancement enabled tighter regulation of cellular functions but meant that cells needed to develop channels to transport proteins, ions, and other substances specifically across their internal and external membranes. Of all of the transport channels in a cell, one stands out from all of the others in terms of the range and size of cargoes that pass through it. This is the NPC, which mediates all transport across the nuclear envelope (NE) (the double-membraned layer that separates the nuclear genetic material from the cytoplasm). Transport through the NPC is rapid and bidirectional, with a large set of diverse cargoes crossing between the nucleus and cytoplasm. Cargoes such as transcription factors, ribosomal proteins, and viral nucleic acids enter the nucleus, whereas, messenger ribonucleoproteins (mRNPs), transfer RNAs (tRNAs), and ribosomal subunits exit. Despite the wide range of molecules that must pass through the NPC, nucleocytoplasmic transport is incredibly selective. Transport can also occur very quickly, up to the order of thousands of events per NPC per second (Ribbeck and Gorlich 2001). Yet the structure of the NPC, discussed below, has been found to be surprisingly simple. How this simple structure might mediate this rapid yet selective transport of such a variety of cargoes remains the main question in the field and is the major topic of this chapter.

\section{SOLUBLE PHASE OF TRANSPORT}

\section{Karyopherin-Mediated Transport}

Numerous lines of evidence have shown that only proteins that can specifically bind to the family of nuclear pore proteins called FG nups are able to efficiently and rapidly cross the NPC. Many such FG-binding proteins act as transport factors, carrying non-FG-binding cargoes across the NPC. Karyopherins (Kaps), also known as importins and exportins, are a family of transport factors that carry proteins and protein/RNA complexes as large as 2 MDa across the NPC (Dworetzky and Feldherr 1988; Adam and Adam 1994; Gorlich et al. 1994, 1995; Macara 2001; Leslie et al. 2002; Pante and Kann 2002; Rout et al. 2003; Mosammaparast and Pemberton 2004; McLane et al. 2008; for review, see Kohler and Hurt 2007; Stewart 2007a). These Kaps recognize their proteinaceous cargo via nuclear localization signals (NLSs) (Goldfarb et al. 1986; Dingwall et al. 1988; Moore and Blobel 1992; Aitchison et al. 1996; Lee and Aitchison 1999; Leslie et al. 2004; Lee et al. 2006; Lange et al. 2007, 2008; Suel et al. 2008) or nuclear export signals (NESs) (Wen et al. 1994; Richards et al. 1996; Ossareh-Nazari et al. 1997; Scheifele et al. 2005; Kosugi et al. 2008; Scott et al. 2009). These signals are exposed on the cargoes and are bound by transport factors that help them to cross the NPC and reach their appropriate destination (Fig. 1, bottom) (Conti et al. 1998; Conti and Kuriyan 2000; Catimel et al. 2001; Chook and Blobel 2001; Lee et al. 2006). Integral inner nuclear membrane proteins appear to be imported in a similar Kap-dependent manner (King et al. 2006).

\section{Ran Gradient and Directionality of Kap-Mediated Transport}

The directionality of Kap-mediated nucleocytoplasmic transport is governed by a concentration gradient of the GTPase (guanosine triphosphatase) Ran across the NE (Fig. 2) (Izaurralde et al. 1997). Kaps can form a complex with RanGTP (concentrated in the nucleus), and this has been seen to trigger the disassembly of import carriers from their cargo and promote the assembly of exportincargo complexes (Fig. 2) (Floer et al. 1997) due to conformational changes in the Kap following RanGTP binding 
The NPC is constructed from several structural layers, each composed of their own distinctive protein fold types.

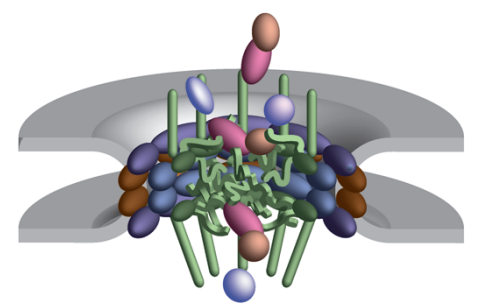

The scaffold proteins form a lattice that resembles vesicle coats (to which it is evolutionarily related). This lattice clasps and stabilizes the curved pore membrane of the NE.

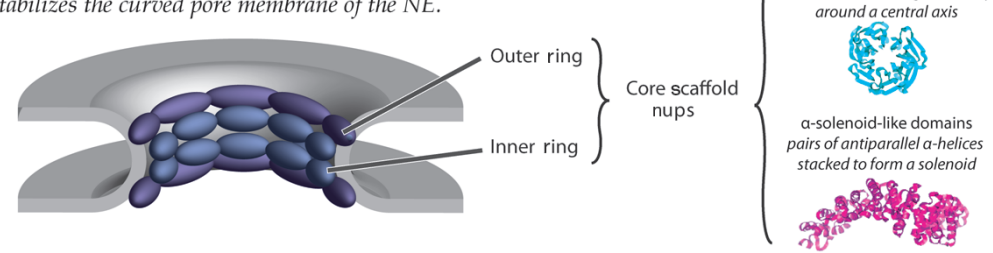

The scaffold is anchored to the pore membrane through a ring of transmembranous proteins that encircle the equator of the NPC.

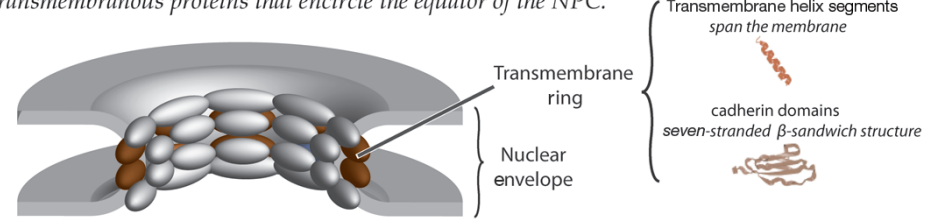

The inner wall of the scaffold, making the NPC's central channel, is lined with the FG nups that form the selective barrier of the NPC.

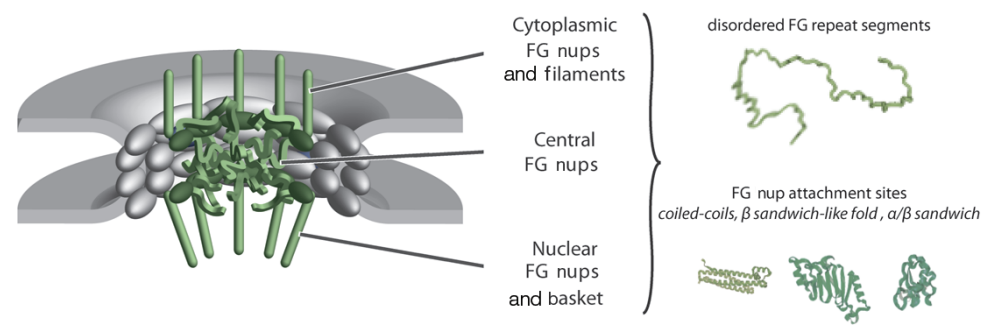

Kaps (and other transport factors) carrying their cargoes compete with each other and with nontransported proteins for passage through the FG nup barrier to cross the NPC.

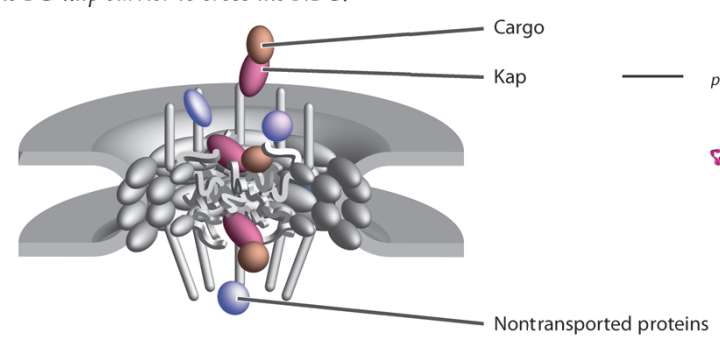

Figure 1. Structure and composition of the NPC. NPC consists of $\sim 30$ proteins containing surprisingly few fold types (see text). Here, nups are colored according to their classification into substructures and fold types and are represented by their localization volumes (Alber et al. 2007a,b). (Left) Protein localization and (right) fold types. (Gray) Pore membrane.

(Cansizoglu and Chook 2007). Conversely, release of Ran following GTP hydrolysis in the cytoplasm results in the assembly of import Kap-cargo complexes and the disassembly of export Kap-cargo complexes (for a review, see Macara 2001). RanGTP also dissociates the import Kap Kap $\beta$ (vertebrate homolog of yeast Kap95) from the NPC (Rexach and Blobel 1995). The difference in concentration of RanGTP between the nucleus and cytoplasm is maintained by the asymmetric localization of the proteins RCC1 and RanBP1. RCC1, the yeast Ran guanidine exchange factor (RanGEF), stimulates the release of guanine nucleotides from Ran by stabilizing the nucleotide-free state (Klebe et al. 1995). Chromatin-bound RCC1 is a constitutively nuclear protein (Ohtsubo et al. 1989), and this local- 


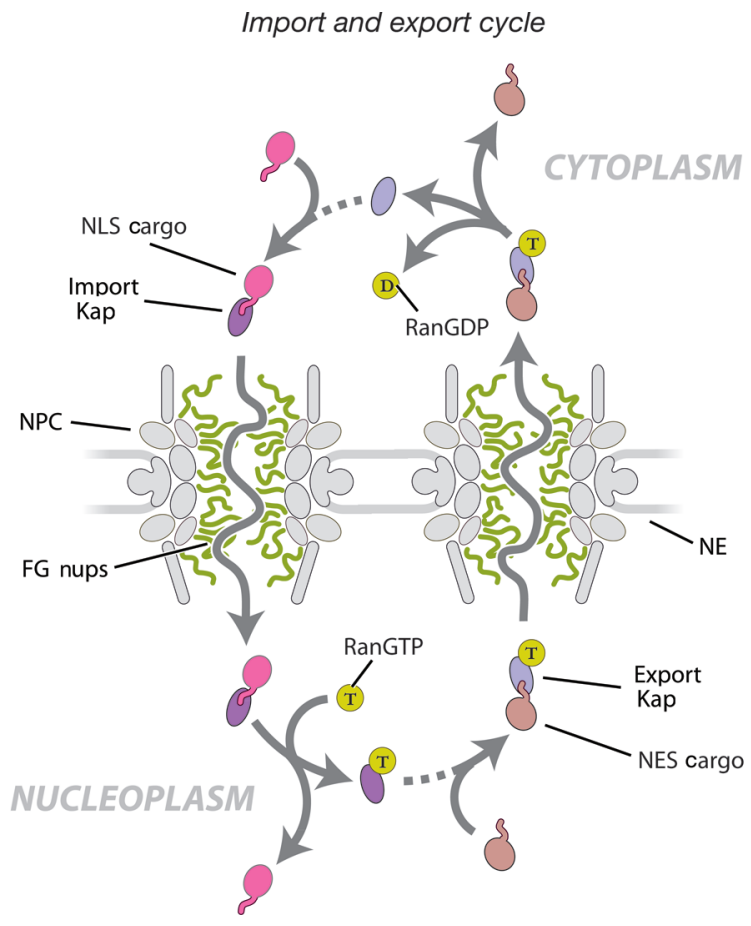

Figure 2. Nuclear transport cycle. As described in the text, directionality of transport through the NPC is controlled by a gradient of RanGTP across the NE. An import Kap (dark purple) binds to its cargo (pink) in the cytoplasm and crosses the NPC by interacting with FG nups (green). Once in the nucleus, RanGTP (yellow circled T) binds, leading to a conformational change that dissociates the Kap-cargo complex. Export Kaps (light purple) form a trimeric complex with cargo (brown) and RanGTP (yellow circled T) in the nucleus. Once in the cytoplasm, RanGAP then triggers hydrolysis of RanGTP into RanGDP (yellow circled D), leading to a conformational change that dissociates the export Kap-cargo complex. RanGDP is then carried back into the nucleus by NTF2 where it is regenerated with GTP to begin another cycle.

ization of the RanGEF ultimately results in a higher RanGTP concentration in the nucleus. The yeast Ran GTPase activating protein (RanGAP) shuttles between the nucleus and cytoplasm (Feng et al. 1999), but Ran-binding protein 1 (RanBP1) is mainly cytoplasmic. RanGAP activity is normally blocked by Kaps (Floer and Blobel 1996; Gorlich et al. 1996), but in the presence of cytoplasmic protein RanBP1, the ability of RanGAP to stimulate RanGTPase activity increases by 10 -fold (Bischoff et al. 1995). Thus, because of the biased localization of RanBP1, cytoplasmic Ran has a much higher GTPase activity than nuclear Ran. When combined with the nuclear RanGEF activity, this leads to a strong RanGTP gradient across the NE, with a high concentration of RanGTP in the nucleus and low levels of RanGTP in the cytoplasm. After each transport cycle, nuclear transport factor 2 (NTF2) carries RanGDP back into the nucleus where it is regenerated into RanGTP (Fig. 2) (Ribbeck et al. 1998; Smith et al. 1998). Thus, the RanGTP gradient across the nuclear membrane distinguishes between nucleoplasm and cytoplasm by promoting different complexes to form on the nucleoplasmic and cytoplasmic sides of the NE. This appears to be the only source of energy for the process of transport because the actual translocation step across the NPC has been shown to be energy independent (Kose et al. 1997; Nakielny and Dreyfuss 1998). A similar mechanism dependent on transport factors and a RanGTP/RanGDP gradient was recently shown to regulate localization of protein to cilia protruding from the cell surface. Similar to NLSs, CLSs (ciliary localization signals) were shown to be sufficient for ciliary targeting in a RanGTP-dependent manner (Dishinger et al. 2010). Thus, it was proposed that the role of Ran may be more universal in directing proteins to their appropriate location.

\section{Transport Factors}

Kaps consist mainly of HEAT or Armadillo repeats stacked on top of one another (see Fig. 1) (Bayliss et al. 2000b, 2002b; Liu and Stewart 2005; for review, see Conti and Izaurralde 2001). Crystal structures and other measurements of Kaps in various stages (with and without nup, RanGTP, and cargo) indicate that these $\alpha$ solenoid structures are dynamic, with rigid elements joined together by flexible hinges (Fukuhara et al. 2004; Matsuura and Stewart 2004; Conti et al. 2006; Cansizoglu and Chook 2007). These conformational changes lead to binding and release of cargoes and other ligands.

Many transport factors are members of the Kap $\beta$ family and thus are structurally similar. For example, the yeast protein Los1 (Hellmuth et al. 1998; Sarkar and Hopper 1998) and its vertebrate homolog exportin-t (Arts et al. 1998; Kutay et al. 1998) are involved in tRNA export (Lipowsky et al. 1999). This Kap $\beta$-like protein binds selectively to end-mature tRNA (Arts et al. 1998; Kutay et al. 1998), helping to ensure that the tRNAs are not allowed to leave the nucleus prematurely (Lund and Dahlberg 1998; Macara 2001). However, other transport factors are not members of the Kap $\beta$ family and are structurally quite different. Some, such as NTF2 (Bullock et al. 1996) and mRNA export protein Mex67 (Fribourg and Conti 2003; Yao et al. 2007), contain an $\alpha+\beta$ barrel that opens at one end to reveal a hydrophobic cavity. Other transport factors such as Arx 1 (which carries the 60S preribosomal subunit) have a characteristic MetAP fold (Bradatsch et al. 2007).

\section{STATIONARY PHASE OF TRANSPORT}

\section{Structure of the NPC}

Despite their structural differences, Kaps, non-Kap transport factors, and other specifically transported proteins all cross the NE through the same conduit, the NPC. This huge, dynamic multiprotein complex spans the double-membraned NE and maintains the selectively permeable barrier between the nucleus and cytoplasm. The large size and intrinsic flexibility of the NPC have made direct structural characterization a challenge. Electron microscopy (EM) has been very useful in determining the overall shape and structure of the complex. The NPC was estimated to range from $\sim 60 \mathrm{MDa}(\sim 100$-nm diameter, $\sim 50$-nm deep) in yeast to $\sim 125 \mathrm{MDa}(\sim 150$-nm diameter, $\sim 70$-nm deep) in vertebrates (Reichelt et al. 1990; Rout 
and Blobel 1993; Yang et al. 1998; Kiseleva et al. 2003; for review, see Wente 2000; Lim et al. 2008b), although the basic shape and structure are conserved between species. These images revealed that NPCs have an eightfold symmetric structure composed of eight spokes and multiple concentric rings (Fig. 1) (Unwin and Milligan 1982; Akey 1989, 1990; for review, see Suntharalingam and Wente 2003; Elad et al. 2009). A central plug has been seen in the EM images of yeast and vertebrate NPCs, although its composition and function are unclear (Jarnik and Aebi 1991; Yang et al. 1998; Kiseleva et al. 2003). It has been interpreted alternatively as a discrete transport channel (termed the "central transporter") (Akey and Radermacher 1993; Yang et al. 1998; Yamada et al. 2010) or as cargo caught in transit (Akey 1990; Stoffler et al. 2003). A set of filaments is seen to extend out from both the cytoplasmic and nucleoplasmic openings of the NPC. On the nuclear side, these filaments contain the protein Tpr in vertebrates (Mlp proteins in yeast cells) (Cordes et al. 1997; Strambio-de-Castillia et al. 1999; Kosova et al. 2000) and are joined by a distal ring to form a basket-like assembly (Stoffler et al. 2003). NPCs must assemble de novo on the reformation of the NE at the end of open mitosis and must be inserted into growing, intact NEs during interphase and in organisms with closed mitosis (such as yeast) (Harel et al. 2003; Walther et al. 2003; Doucet et al. 2010). Once formed, the NPC channel is stable, with many structural proteins exhibiting lifetimes that may stretch upward of years, at least, in certain postmitotic cell types (D'Angelo et al. 2009). In contrast, many of the peripheral proteins are transients, spending significant amounts of time in the nucleoplasm and cytoplasm and exhibiting very rapid turnover rates at the NPC (Denning et al. 2001; D'Angelo et al. 2009; Capelson et al. 2010; Wickramasinghe et al. 2010).

The NPC was expected to contain up to hundreds of different proteins, based on its large size (e.g., given the $\sim 60$ proteins in the 2 -MDa ribosome; Davis 1995; Arnold and Reilly 1999). Therefore, it was surprising when a survey of yeast NPC components identified only $~ 30$ different protein components (termed nucleoporins [nups]) (Rout et al. 2000). A similar simple composition has been found in all organisms studied (Cronshaw et al. 2002; DeGrasse et al. 2009). The large mass of the NPC comes from the repetition of these building blocks, with each of the $~ 30$ nups being present in 8,16 , or 32 copies per NPC, i.e., with one, two, or four copies per spoke (Rout et al. 2000; Cronshaw et al. 2002; Alber et al. 2007a,b). On the basis of primary sequence analysis and protease accessibility assays, folds were assigned to $>95 \%$ of the NPC residues (Devos et al. 2006). These fold assignments revealed a surprising underlying simplicity to the architecture of the NPC. The $~ 30$ nups are made up from combinations of only eight fold types, with the three most common fold types ( $\alpha$-solenoid, $\beta$-propeller, and natively unfolded) describing $85 \%$ of the residues (Devos et al. 2006). Crystal structures have upheld these fold predictions and continue to shed light on the detailed structures of individual nups (Hodel et al. 2002; Berke et al. 2004; Weirich et al. 2004; Hsia et al. 2007; Melcak et al. 2007; Napetschnig et al. 2007, 2009; Debler et al. 2008; Leksa et al. 2009; Nagy et al. 2009; Seo et al.
2009; Whittle and Schwartz 2009; for review, see Madrid and Weis 2006; Blobel, this volume).

\section{Structural Nups Form a Scaffold}

More than half of the mass of NPC proteins is predicted to be composed of a combination of $\beta$-propeller and $\alpha$-solenoid-like motifs (Devos et al. 2004, 2006; Alber et al. $2007 \mathrm{a}, \mathrm{b})$. These $\alpha$-solenoid-like domains are similar to the superhelices of $\alpha$-solenoid-like repeats found in the Kaps (Bayliss et al. 2000b, 2002b; Fukuhara et al. 2004; Matsuura and Stewart 2004; Liu and Stewart 2005; Conti et al. 2006; Cansizoglu and Chook 2007; for review, see Conti and Izaurralde 2001). Interestingly, this common architecture may indicate an evolutionary link between the nups that make up the NPC and the transport factors that pass through the NPC (Fig. 1) (Devos et al. 2006). Significantly, proteins containing mainly $\alpha$-solenoid-like domains have been shown to be flexible, exhibiting large conformational changes following ligand binding and unbinding (Conti et al. 2006). This structural flexibility may enable broad conformational changes without breaking protein-protein interactions. The structural flexibility of the $\alpha$-solenoid nups could explain, at least in part, the multiple conformations of the NPC observed in EM (Akey 1990; Akey and Radermacher 1993; Berke et al. 2004; Alber et al. 2007b).

Outside of the NPC, the combination of amino-terminal $\beta$-propeller and carboxy-terminal $\alpha$-solenoid-like domains is found in eukaryotic proteins associated with coated vesicles, where they are proposed to function as a scaffold, stabilizing curved membranes (ter Haar et al. 1998; Kirchhausen 2000; Devos et al. 2004; for review, see Bonifacino and Glick 2004). A map of the NPC (Alber et al. $2007 a, b)$ indicated that clathrin- and adaptin-like proteins are arranged in a fashion somewhat reminiscent of the scaffold found in clathrin-coated vesicles (Figs. 1 and 3) (Collins et al. 2002; Evans and Owen 2002). In fact, all three major classes of membrane-coating complexes (the NPC, clathrin-coated vesicles, and COP I/II-coated vesicles) share key elements of this common architecture (Salama et al. 1997; Schledzewski et al. 1999; Shugrue et al. 1999; Belden and Barlowe 2001; Boehm and Bonifacino 2001; Devos et al. 2004, 2006; Fath et al. 2007; Lee and Goldberg 2010). This observation led to the hypothesis that all three membrane-curving complexes are evolutionarily related (Devos et al. 2004, 2006; Field and Dacks 2009). It has been proposed that early in the evolution of eukaryotes, an ancestor first developed a "protocoatomer," namely, an arrangement of scaffold proteins that was able to produce and maintain curvature in internal membranes (Blobel 1980; Devos et al. 2004, 2006; Field and Dacks 2009). On the basis of the endomembrane hypothesis (Blobel 1980), the protocoatomer suggests that the development of these scaffolds enabled the formation of vesicles and the compartmentalization of the cell into membranebound organelles. This protocoatomer may then have evolved into the NPC, clathrin/adaptin, and COP I/II, the different types of membrane-curving scaffolds found in modern eukaryotes (Devos et al. 2004, 2006).

The yeast NPC scaffold is anchored into the NE by three transmembrane proteins (Alber et al. 2007b; Oni- 


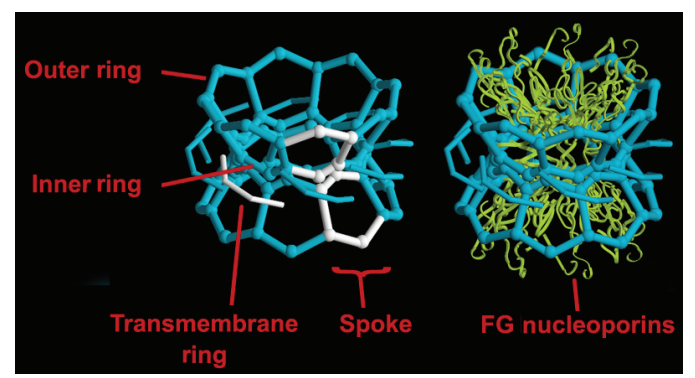

Figure 3. Structural nups form a clathrin-like scaffold. (Left) Schematic shows how the inner and outer ring proteins of the NPC (see Fig. 1) could be connected to form a clathrin- or coatomer-like scaffold (blue), serving to maintain curvature of the NE to which it is attached via the transmembrane ring proteins. (White) One of the eight spokes of the NPC. (Right) The hole defined by the scaffold is lined with natively unfolded FG nups (green). Connections forming this scaffold could be very transient or even discontinuous, permitting, e.g., the nucleocytoplasmic trafficking of transmembrane proteins and allowing the dynamic association of various nups.

schenko et al. 2009). A recent map of the yeast NPC has shown that this scaffold is modular and repetitive (Figs. 1 and 3), with each half-spoke containing proteins in duplicate copies or homologous pairings. This led to the suggestion that the simple and symmetric structure of the NPC is the result of a series of gene duplications and other elaborations from the original ancestral protocoatomer (Alber et al. 2007a,b).

Consistent with its proposed early evolution, the composition, modularity, and basic structure of the NPC has been shown to be conserved across eukaryota, e.g., from amoeba (Beck et al. 2004, 2007) to fungi (Yang et al. 1998; Rout and Field, 2001; Kiseleva et al. 2003; Alber et al. 2007b; Hsia et al. 2007; Patel et al. 2007; Debler et al. 2008; Frenkiel-Krispin et al. 2010), to the animal kingdom (including nematodes [D'Angelo and Hetzer 2008; D'An- gelo et al. 2009] and vertebrates [Akey and Radermacher 1993; Berke et al. 2004; Boehmer et al. 2008; Stoffler et al. 2003]), and even to the most divergent eukaryotic taxa (e.g., Trypanosoma brucei) (DeGrasse et al. 2009).

Conspicuous by their absence from the NPC are the motor proteins, ATPases, GTPases, or chemosensors normally associated with transport (Rout et al. 2000; Cronshaw et al. 2002). This was very surprising - it was almost as if we opened the hood of a car expecting to see the engine but only found scaffolding and string. How does the NPC create such a selectively permeable barrier without any motor proteins or other mechanism to physically open and shut a gate? The answer to this question appears to be provided by the behavior of a family of proteins collectively termed FG nups. These proteins specifically interact with molecules to be transported.

\section{Structure and Composition of FG Nups}

FG nups, so called because they contain large domains carrying many characteristic FG repeats (for review, see Rout and Wente 1994; Allen et al. 2001; Tran and Wente 2006; Peters 2009b; Terry and Wente 2009), are perfectly positioned to form the selective barrier of the NPC, because they line the central channel and flank its entrances (Figs. 1 and 2) (Rout et al. 2000; Alber et al. 2007b). Several lines of evidence point to a natively unfolded structure for the FG repeat regions in FG nups. Gel filtration and sucrose gradient sedimentation indicated that the FG domains of these proteins have large hydrodynamic radii, consistent with nonglobular noncompact structures (Figs. 1 and 4) (Denning et al. 2003). Furthermore, circular dichroism (CD) and Fourier transform infrared (FTIR) spectroscopy showed that the FG domains lack structured regions, such as $\alpha$ helices or $\beta$ sheets (Denning et al. 2003). FG domains have also been shown to be highly accessible to proteinase $\mathrm{K}$ digestion (Denning et al. 2003), typical of proteins that are natively unfolded. Finally, the lack of secondary structure was further
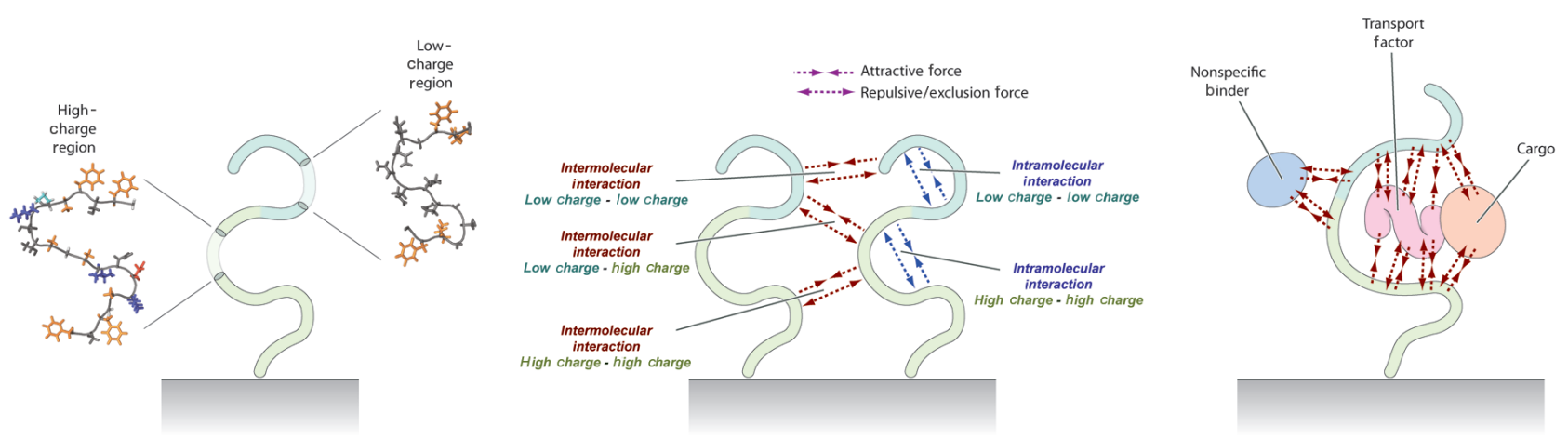

Figure 4. Inter- and intra-FG interactions. (Left) FG repeats consist of regions of high charge (high DERK content) (green) and low charge (low DERK content) (blue). Molecular structures shown are from portions of FG nups Nsp1 (high charge) and Nup100 (low charge), with hydrophobic residues (orange) and negatively and positively charged residues (red and blue), respectively; these structures illustrate how most residues in FG nups have small side chains, with the exception of phenylalanine residues (orange hexagons), which extend significantly from the backbone. (Center) Interactions between FG repeats can be attractive or repulsive (see text). These attractive and repulsive interactions can occur within an FG repeat region (blue arrows) or between different regions (red arrows). Relative strengths of these different types of interactions are unknown and determine FG nup behavior. (Right) Kaps and specifically transported molecules are able to cross the NPC because they can interact with FG nups. Phenylalanine side chains insert into hydrophobic pockets on the surface of transported proteins. It is thought that specifically transported proteins contain hydrophobic pockets in the correct arrangement to enable multiple phenylalanines from the same FG nup to make contact, whereas nontransported proteins will only have one or two interactions from the same FG nup (red arrows). 
confirmed in vitro by atomic force microscopy (Lim et al. 2007a,b, 2008a). These studies showed that the FG domain of the mammalian Nup153 can be reversibly stretched and relaxed without any changes in elasticity. Thus, the FG repeat domains were compared with worm-like chains (Lim et al. 2007a,b, 2008a). The persistence length was found to be $\sim 4 \AA$ or approximately one amino acid residue, providing additional evidence of the incredible flexibility of this domain (Lim et al. 2006). This flexibility could translate in vivo to tremendously dynamic behavior, with the flexible domains rapidly sampling many different conformations. The natively unfolded FG domains are typically attached to a small structured domain, such as a coiled coil or a $\beta$ sandwich (for references, see Devos et al. 2006). This structured domain serves to anchor the FG nups to the NPC but may also contain other functional domains. For example, the yeast FG nups Nup53 and Nup59 contain RNA recognition domains (Devos et al. 2006; Handa et al. 2006), whereas Nup145N, Nup100, and Nup116 contain the autocatalytic domain of Nup98 (Hodel et al. 2002; Robinson et al. 2005; Devos et al. 2006; Sampathkumar et al. 2010).

FG nups have been found in all eukaryotic organisms studied; even the divergent $T$. brucei, which branched off of the eukaryotic tree 1-2 billion yr ago (Beverley 2003), contains these proteins (DeGrasse et al. 2009). The overall fold type, domain organization, amino acid composition, and modularity in the FG nups also seem to be highly conserved across eukaryotes (Cronshaw et al. 2002; Denning 2007; Yamada et al. 2010). In all species in which they have been identified, these FG repeat regions are consistently enriched in disorder-associated amino acids (such as $\mathrm{A}, \mathrm{R}, \mathrm{G}, \mathrm{Q}, \mathrm{S}, \mathrm{P}, \mathrm{E}$, and $\mathrm{K}$ ) and depleted in order-producing amino acids (such as W, C, I, Y, V, L, and N), indicating that the unfolded nature of these repeat regions is highly conserved (Denning and Rexach 2007). In fact, the only order-promoting amino acid in which these FG-rich domains are enriched is phenylalanine itself (Denning and Rexach 2007). In all eukaryotes, the FG repeat domains seem to divide into two flavors: Those low in glycine are enriched in charged residues (D, E, R, K), whereas those high in glycine are depleted of charged residues (Fig. 4) (DeGrasse et al. 2009). Because many aspects of these FG nups are so highly conserved across eukaryota (Feldherr et al. 2002), their function and mechanism must have evolved early and remained relatively unchanged for millennia. However, although the natively unfolded nature of these FG repeat domains is highly conserved, the primary amino acid sequences separating FGs vary to a much larger degree than those between homologous structured proteins. This sequence variability may be due to weak constraints on particular amino acid usage in natively unfolded domains. Because there is no secondary structure to maintain, natively unfolded domains can withstand changes in primary sequence to a larger extent than globular proteins (Brown et al. 2002; Denning 2007).

\section{Interactions between FG Repeats}

Because FG nups comprise the permeability barrier of the NPC, much work has been done to understand their mechanism of action. Whereas the natively unfolded nature of the FG repeat regions is widely accepted in the field, the exact behavior of the FG nups in vivo remains controversial. As with many unfolded polymers, entropic effects as well as hydrophobic, hydrophilic, and electrostatic interactions both within and between each FG repeat region (Gehrke et al. 1997; Kawai et al. 2003) are expected to govern FG nup behavior. However, the relative strength and importance of these interactions remain unclear (Fig. 4). Current models of FG nup function differ in the types of interactions that are proposed to dominate. FG repeat regions could attract one another through, e.g., hydrophobic interactions between their Phe (or other) residues (Ribbeck and Gorlich 2002) or through electrostatic interactions, as do some synthetic polyelectrolytes (Taylor et al. 2007). A model in which these attractive interactions strongly dominate predicts that the FG nups would form a rigid hydrogel or a selective phase (Ribbeck and Gorlich 2002; Frey et al. 2006; Frey and Gorlich 2007, 2009) through which only certain molecules could partition, and indeed these proteins can be made to form such a gel in vitro (Frey et al. 2006; Frey and Gorlich 2007, 2009). The FG regions might also repel one another because of their net positive charge or "entropic exclusion" (the thermal motion of the unstructured filaments causes them to fill up a large volume around their tether site; molecules that occupy a significant portion of this tend to be excluded from this volume [Brown and Hoh 1997]). If repulsive interactions dominate, the densely packed FG nups in the NPC could behave collectively as a polymer brush, creating an entropic barrier that excludes material via steric repulsion. Such entropic exclusion behavior has been measured for these proteins in vitro (Rout et al. 2000, 2003; Lim et al. 2006, 2007a,b; Lim and Deng, 2009; Miao and Schulten 2009). If interand intra-FG repeat attractions were modified by entropic exclusion, hybrid models would be possible. A dual gate model proposes that some inter- and intra-FG domain interactions can be attractive, whereas others are repulsive, such that brushes and cohesive regions coexist within the central channel of the NPC (Patel et al. 2007; Patel and Rexach 2008). The reduction of dimensionality (Peters 2005, 2009b) or "oily spaghetti" model (Macara 2001) posits that inter- and intra-FG attractions are strong enough to cause the natively unfolded FG domains to collapse, forming a layer along the walls of the NPC channel. This layer would be impenetrable to inert molecules, thus decreasing the effective diameter of the channel for these molecules, but would prove no barrier to transport factors. An observation that FG nups may collapse following Kap binding supports this proposal (Lim et al. 2007a). It must also be noted that FG nups in vivo are grafted close together on a surface, which greatly modifies the behavior of some polymers relative to their behavior in free solution (Bright et al. 2001). Attraction, repulsion, or a mixture of both, could occur within the same molecule or between different molecules; they could be between the same "flavor" of FG repeat or different ones (Fig. 4, center). Changing the relative strength of any combination of these forces could lead to dramatically different dynamic behaviors of the FG nups. 
Much work has been done to characterize inter- and intra-FG domain interactions. Molecular dynamic simulations have suggested that individual FG domains form dynamic globular structures, whereas arrays of tethered domains form brush-like bundles (Miao and Schulten 2009). When in isolation in solution, different FG domains have recently been shown to range from collapsed coil to extended coil. The extent of flexibility of a given domain appears to depend on the ratio between charged and hydrophobic residues (Yamada et al. 2010). Solid-state nuclear magnetic resonance (NMR) studies of an FG domain hydrogel have shown that highly charged segments are mobile and unstructured, whereas segments with lower charge are more rigid (Ader et al. 2010). Some FG domains are bipartite, consisting of an extended highly charged "stalk" region attached to a more compact collapsed-coil region with lower charge. This finding has led to the "forest" model of FG nup distribution in which highly charged collapsed-coil FG domains lining the walls of the NPC would be considered "bushes" and the bipartite FG domains would be considered "trees" (Yamada et al. 2010). In the bipartite domains, a collapsed region of low charge is thought to be held at a distance from the anchor site by a highly charged extended region. The collapsed "tree tops" from the bipartite FG domains might combine to form the central transporter that was observed in the EM (Akey 1990; Yamada et al. 2010). Alternatively, and more simply, this ring of high density may result from the fact that FG nups are natively unfolded proteins anchored around the edge of a cylindrical channel.

A problem with piecing together FG nup behaviors within the NPC is the wide range of observed in vitro behaviors that can even be contradictory. For example, when in a highly concentrated solution, Frey et al. (2006) observed the yeast FG nup Nsp1 form a selectively permeable saturated hydrogel (Frey et al. 2006; Frey and Gorlich $2007,2009)$. However, this same protein was among those found to be noncohesive when tethered to sepharose beads (Patel and Rexach 2008). When the vertebrate FG nup Nup153 was attached to a gold surface, Lim et al. (2006) observed that it exhibited polymer brush-like behavior with no internal cohesive forces, although Yamada et al. (2010) reported that different FG nups exhibit distinct levels of compactness in solution due to internal cohesive forces. These often-conflicting observations have indicated that FG nup behavior in vitro is dependent on experimental conditions and leave many questions as to the exact physical nature of the permeability barrier. Thus, characterization of the type and strength of the intermolecular and intramolecular FG repeat interactions, particularly as they exist in the context of the NPC, remains a major goal for the field. However, many of the basic principles of transport can perhaps be understood without knowing the exact nature of the interactions between FG repeat domains.

\section{Details of Interactions between FG Nups and Transport Factors}

FG nups enable the selective passage of molecules with which they interact (Iovine et al. 1995; Radu et al. 1995a,b; Bailer et al. 1998; Marelli et al. 1998; Bayliss et al. 1999, 2000a,b, 2002a,b; Ben-Efraim and Gerace 2001; Strawn et al. 2001; Gilchrist et al. 2002; Gilchrist and Rexach 2003; Grant et al. 2003; Morrison et al. 2003; Isgro and Schulten 2007a,b). Crystal structures indicate that phenylalanine side chains of the FG repeats are buried in hydrophobic pockets on Kaps (Bayliss et al. 2000b, 2002b; Liu and Stewart 2005) and non-Kap transport factors such as Mex67 (Grant et al. 2003) and Ntf2 (Bayliss et al. 2002a). The importance of such hydrophobic interactions to the transport mechanism is supported by the recent finding that modifying the surface of bovine serum albumin (BSA) to make it more hydrophobic allows the normally nontransported protein to enter the nucleus of permeablized HeLa cells (Naim et al. 2009). Whereas the phenylalanine side chains are well resolved in the crystal structures, the often highly charged spacer sequences separating the FG repeats are not (Bayliss et al. 2000b, 2002b; Liu and Stewart 2005). This indicates that, unlike phenylalanines, these spacer amino acids are not held in a constant conformation when the FG repeat peptide is bound to Kap. However, it has recently been suggested that these charged regions and their electrostatic interactions are still important for transport selectivity through interactions with transport factors (Colwell et al. 2010).

Molecular dynamics simulations of transport factor/FG nup binding verified previously observed binding sites while identifying potential novel ones (Isgro and Schulten 2005, 2007a,b). Multiple ( 10) hydrophobic-binding pockets were observed on the surface of each transport factor tested in these simulations, and these were often occupied simultaneously by multiple phenylalanines from the same FG repeat peptide (Fig. 4, right). Again, this was true for Kap-like proteins (such as importin $\beta$; Isgro and Schulten 2005) and non-Kap transport factors (such as NTF2; Isgro and Schulten 2007a). This led to the proposal that transport factors are able to cross the NPC because they have the proper number of hydrophobic pockets distributed appropriately along the surface of the protein to enable multiple phenylalanines to bind simultaneously from a single FG nup, whereas nontransiting molecules may only have, at most, one or two patches that bind to FG repeats, an insufficient amount for them to overcome the barrier and cross the NPC (Fig. 4, right) (Bayliss et al. 2000b, 2002a,b; Isgro and Schulten 2005, 2007a,b).

To summarize, the NPC consists of a scaffold supporting a layer of FG nups. The FG nups line the central channel of the NPC and contain binding sites for transported molecules. Therefore, at its most basic level, the NPC may be considered simply a hole defined by a scaffold, filled with FG-binding sites. But the question remains: How does a hole filled with FG nups create a selectively permeable barrier?

To begin to explore this question, one might start by picturing two compartments containing large and small molecules that are separated by a long thin channel (Fig. 5C). The NPC may be considered such a channel connecting the nucleus and cytoplasm. Movement of molecules within and between the compartments occurs via simple diffusion. Diffusing molecules can be considered to take 
a series of discrete steps, with the direction of each step independent of the previous step, i.e., a random walk (Berg 1993). To pass from one compartment to the other, a molecule must first find the small channel opening. A molecule freely diffusing in three dimensions will encounter a small hole of radius $R$ at the rate $4 D R$ (Hill 1975 ), where $D$ is the diffusion constant of the molecule. Because $D$ is inversely dependent on size (Grathwohl 1998), larger molecules encounter the channel opening at a slower rate than do smaller molecules. In addition, as the size of a particle increases, approaching the channel diameter, the probability that an encounter with the opening will be productive (i.e., allow entry) decreases. Thus, the relatively small diameter of a channel, such as the NPC compared with its surroundings, decreases the flux of particles in a size-dependent manner, even if the channel diameter is large enough for the molecules to easily pass through (Purcell 1977; Berg 1993; Rout et al. 2003; Zilman et al. 2007, 2010). In the NPC, FG nups occupy space within the channel and effectively decrease the channel diameter, enhancing this effect.

A
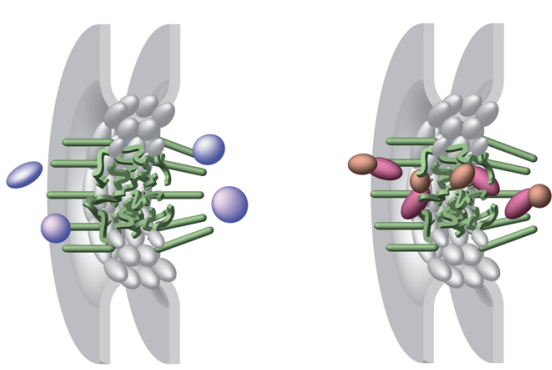

B

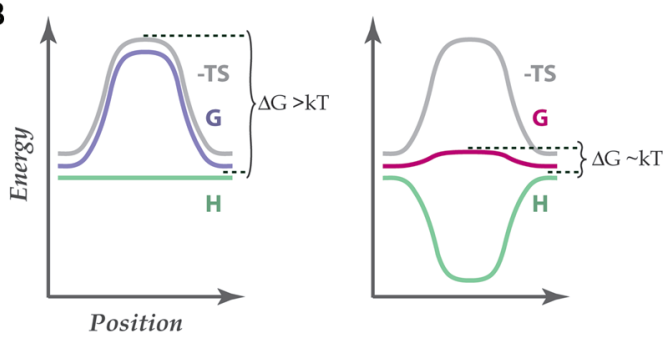

C

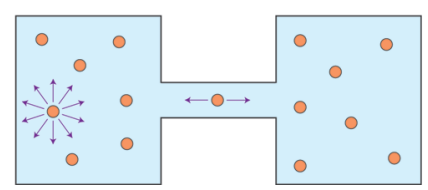

Figure 5. Energetics of nucleocytoplasmic transport. (A) An NPC and NE (gray) with FG nup-containing regions highlighted (green). Illustrations of a nonbinding molecule (left, violet) and an FG-binding Kap-cargo complex of similar size (right, pink). Unlike the nonbinding molecule, the binding complex is able to efficiently penetrate the FG nup barrier and cross the NPC. $(B)$ The enthalpy of binding to FG nups creates a zone of high concentration around the entrance to the NPC, enabling Kaps and other specifically transported molecules to overcome the entropic barrier and enter the NPC (see text). (C) Schematic illustrates the likelihood that a molecule having entered the NPC will exit at the other side. A molecule in the cytoplasm has free range of diffusive motion and an equal probability to step in any direction. A molecule confined in the small space of a channel is limited mainly to forward and backward diffusive steps (see text).
Once a molecule to be transported has overcome the first obstacle and successfully entered the channel, it must cross the length of the channel to exit at the other side. In the simplest case of one-dimensional diffusion within a thin channel, a particle is limited to forward and backward steps (Fig. 5C). If a molecule were to enter the channel from the left side, each step in its subsequent random walk has an equal probability of going to the left or to the right. Therefore, it is more likely that the molecule will ultimately exit the channel at the left (i.e., the same way that it entered) rather than make its way across and exit at the right. To understand why this is so, imagine a coin being tossed 10 times. It is highly unlikely that all 10 tosses will land on heads. It is much more likely that some of those tosses will result in heads and some in tails. Analogously, if a molecule takes 10 steps within the channel, with each step having an equal probability of being forward or backward, it is more likely that the molecule will end up fewer than 10 steps away from where it started. The length of a channel, such as the NPC therefore, poses a barrier to transport because a diffusing molecule is less likely to completely cross a longer channel than a shorter one.

The diameter and length effects described above have a role in the passage of a molecule through any channel. However, the NPC is not an empty channel - much of its volume is occupied by the FG nups. These proteins are natively unfolded and highly dynamic (Denning et al. 2003; Miao and Schulten 2009; Yamada et al. 2010) and must move out of the way for large molecules to pass through the NPC. Extended FG nups tethered to a surface have even been seen to collapse after incubation with Kaps (Lim et al. 2007a). This unfavorable decrease in entropy of the FG nups required to make space for transported molecules creates a thermodynamic barrier inhibiting passage through the NPC. These three factors - the small diameter of the channel, the length of the channel, and the thermodynamic barrier-form the basis of the NPC's selectivity.

\section{Binding Can Overcome Barriers to Passage through the NPC}

Alone, a simple channel cannot provide the impressive selectivity achieved by the NPC: After all, there is nothing to distinguish between transported and nontransported factors of similar size. The key to selective transport through the NPC is the binding of transported molecules to the FG nups. An advantage of using natively unfolded filaments as binding sites is that only a small amount of protein is needed to fill a large amount of volume, such that a small amount of protein produces a huge binding site. Indeed, the FG nups could behave like antennae, reaching out as a "cloud" of binding sites many tens of nanometers from the nuclear and cytoplasmic faces of NPCs. This cloud could efficiently funnel transport factors and their cargoes into the NPC while simultaneously generating a zone of exclusion for nonbinding molecules around the NPC. The vicinity of the NPC may therefore be a very special zone, enriched in transport factors and depleted in nonbinding molecules, with a composition quite different from the surrounding cytoplasm and nucleoplasm. Enrichment of binding molecules around the channel entrances would increase the 
likelihood of a binding molecule entering the channel while decreasing the entrance probability of a nonbinding molecule. This idea is supported by single-molecule measurements, which indicate that even for the largest cargoes such as mRNA export complexes, transport through the NPC is very fast ( $20 \mathrm{msec}$ ), but there is an $\sim 80$-msec delay at both the entry and exit (Grünwald and Singer 2010). This delay could indicate that the transport complex interacts with peripheral FG nups to remain close to the entrance and waits its turn until an interior binding site opens up, allowing it to enter the pore. In addition, cytoplasmic filaments were seen to increase the capture area for transport-competent quantum dots in permeabilized HeLa cells (Lowe et al. 2010). This role of funneling cargo into the NPC has been proposed for the FG nups that comprise the cytoplasmic filaments of the NPC (Minakhina et al. 2005; Hutten et al. 2009; Strambio-De-Castillia et al. 2010).

Once a molecule to be transported has entered the channel, it must cross the length of the channel and exit at the other side. If a long channel separating two chambers is filled with binding moieties for certain molecules, it can facilitate selective transport of molecules that bind. If only one type of molecule is present in the two chambers, the presence of binding sites for that molecule within the channel increases the probability that a molecule, once entered, will cross the channel and exit at the other side. This is because the presence of binding sites within the channel initially biases the random walk of the molecule toward the middle, preventing it from returning to where it came (Berezhkovskii et al. 2002; Berezhkovskii and Bezrukov 2005; Zilman 2009; Zilman et al. 2007, 2010), rather as if "heads" were now strongly weighted at the entrance of the channel in the coin analogy. If binding and nonbinding molecules are both present in the chambers, the binding molecules enriched within the channel occupy space, increasing the likelihood that a nonbinding molecule will exit at the same side from which it entered, rather than making it all the way across the channel (Zilman et al. 2010).

Finally, in the specific case of the NPC, the negative enthalpy change of binding can overcome the entropic cost of compressing the FG nups. Recall that the Gibbs free energy of a system $(\Delta G)$ is related to the change in enthalpy $(\Delta H)$ and entropy $(\Delta S)$ by $\Delta=\Delta H-\Delta S$. A heuristic understanding of selective transport posits that the negative $\Delta H$ following binding will lower the Gibbs free energy of transport for molecules that can bind to FG nups (Fig. 5A,B, right) (Rout et al. 2003; Nielsen et al. 2006). This heuristic view is the essence of the "virtual gating" mechanism (Rout et al. 2003). Heuristically, all three effects described above (compression, entrance, and translocation) can be viewed as entropic in origin (and the enthalpic gain from binding helps to overcome all three), regardless of the conformational change of the FG nups that occurs after entrance of a particle into the channel (Lim et al. 2007a; Eisele et al. 2010). To summarize, the NPC may be considered a long channel filled with FG nups. The geometric barriers imposed by the NPC diameter and length and the thermodynamic barrier imposed by the compression of FG nups are overcome by the binding of transported molecules to FG nups, enabling rapid, efficient, selective transport through the NPC.

\section{Channels Lined with Binding Sites Have Been Shown to Mediate Selective Transport}

The ability of a simple pore lined or filled with binding sites to enable selective transport was tested experimentally by monitoring flux of molecules through membranes perforated with inert holes or holes lined with binding sites for the cargo to be transported. A pore lined with an apoD-amino acid oxidase (inactive without its cofactor) can select between D- and L-phenylalanine (Lakshmi and Martin 1997). Nanotubes lined with stereospecific antibodies have been shown to select between enantiomers of a chiral drug (Lee et al. 2002). A narrow margin of affinities for binding sites was found that can enable selective yet rapid transport. It is thought that the affinity has to be sufficiently strong for selection but weak enough not to clog the pores (Macara 2001; Nielsen et al. 2006; Zilman et al. 2007). Transport channels coated with hairpin DNA have been shown to transport the complimentary oligos with singlebase mismatch selectivity (Kohli et al. 2004). A self-interacting polymer, polyisopropylacrylamide (pNIPAM), was shown to facilitate its own transport through a pNIPAMlined pore. Single-stranded DNA (ssDNA) conjugated to a mobile pNIPAM polymer was able to cross this modified pore more efficiently than the ssDNA alone, thus replicating the phenomenon of transport-factor-assisted passage (Caspi et al. 2008). Thus, a simple hole lined with binding sites was shown to preferentially transport cargoes that can interact with the binding sites over cargoes that cannot.

\section{A Channel Lined with FG Nups Has Been Shown to Mediate Selective Transport}

The ability of a simple hole lined with FG domains to be a selective gate was also tested experimentally. A membrane with $\sim 30$-nm-diameter pores that was coated with the FG domain of the yeast FG Nup Nsp1 allowed rapid transport of a karyophillic molecule (NTF2-GST) while simultaneously inhibiting passage of an inert molecule of similar size (BSA) (Jovanovic-Talisman et al. 2009). Kapmediated transport was also replicated in this artificial system by using importin $\beta$-binding domain-green fluorescent protein (IBB-GFP), a fluorescent cargo of the yeast Kap, Kap95 (Timney et al. 2006). When in a complex with Kap95, IBB-GFP was seen to cross the functionalized nanopores much more efficiently than green fluorescent protein (GFP) alone, although the Kap/IBBGFP complex is nearly four times the mass of the GFP (Jovanovic-Talisman et al. 2009). As expected, selectivity of these membranes was seen to diminish as pore diameter increased and to improve after increasing the thickness of the FG nup layer (Jovanovic-Talisman et al. 2009). These trends were expected because increasing pore size decreases concentration of FG nups within the pore, and increasing the thickness of the FG nup layer increases the amount of FG nups lining the channel (Jovanovic-Talisman et al. 2009). Binding strength of the transport factor to the FG repeats was also shown to influence membrane selectivity. When the affinity of the transport factor to the FG nup was reduced, the difference in flux between transport factor and nonbinding protein decreased (Jovanovic- 
Talisman et al. 2009). Interestingly, the selectivity of this functionalized membrane was only seen when the transport factor and nonbinding (or weakly binding) protein were simultaneously facing the membrane. When no FG nup-binding molecule was present, BSA went through the functionalized pores relatively unimpeded (JovanovicTalisman et al. 2009). This led to the hypothesis that competition for space within the pore leads to selectivity, which is further discussed below.

\section{Measurement of Kap-FG Nup Binding In Vitro}

The experiments and theory described above support the idea that Kaps and other specifically transported molecules cross the NPC by interacting with the phenylalanine side chains of FG nups (Iovine et al. 1995; Radu et al. 1995a,b; Bailer et al. 1998; Marelli et al. 1998; Bayliss et al. 1999, 2000a,b, 2002a,b; Ben-Efraim and Gerace 2001; Strawn et al. 2001; Gilchrist et al. 2002; Gilchrist and Rexach 2003; Grant et al. 2003; Morrison et al. 2003; Liu and Stewart 2005; Bradatsch et al. 2007; Isgro and Schulten 2007a,b; Hung et al. 2008). We largely understand the basic thermodynamics behind selective transport, but the details of how binding between transport factors and FG nups facilitates their passage are unclear. This is analogous to understanding that an enzyme catalyzes a reaction by stabilizing the transition state and lowering the activation energy of the reaction but not knowing the structure of the enzyme or the exact mechanism of its action. Interactions between transport factors and FG nups have been difficult to study in vitro. As they are natively unfolded, the FG domains are not well resolved in crystal structures, and how does one study the structure of an unstructured protein? In addition, large enough quantities of full-length FG nups for in vitro experiments are very difficult to obtain. Because these proteins contain natively unfolded domains, they are highly sensitive to proteolysis and are often difficult to express full length in Escherichia coli (see, e.g., Gilchrist et al. 2002). For this reason, many in vitro studies of Kap/FG nup interactions have been performed using small well-behaved fragments of these FG domains. However, this can also lead to some confusion because different fragments of the same FG nup exhibit widely different apparent affinities to the same transport factor. For example, residues 332-1076 of the yeast FG nup Nup1 bound Kap95 with a Kd of $8 \mathrm{nM}$, whereas, residues 332-1040 of Nup1 bound Kap95 with a Kd of $2500 \mathrm{nM}$, a difference of 300 -fold (Pyhtila and Rexach 2003). Worse, even if the exact same amino acids are included in the FG nup portion used, affinities measured in vitro using different techniques do not necessarily agree. For example, the interaction between Imp $\beta$ (mammalian homolog of yeast Kap Kap95) and p62 (mammalian homolog of yeast FG nup Nsp1) was measured to be $100 \mathrm{nM}$ by microtiter plate-binding assay (Ben-Efraim and Gerace 2001) and $8 \mathrm{nM}$ by surface plasmon resonance (Lott et al. 2010). This underscores the point that FG nup behavior in vitro - in this case, binding - is dependent on experimental conditions. Recently, it has been suggested that affinity between Kaps and FG domains may depend on the density of FG domains on a surface (Peleg and Lim 2010). This may help to explain some of the discrepancies between these two measurements. The presence of cargo has also been suggested to influence Kap/FG nup binding, perhaps due to conformational changes in the Kap after binding to cargo. However, this effect of cargo is confusing. On one hand, the presence of Kap60 was shown to increase the affinity of Kap95 to Nup1 from $8 \mathrm{nM}$ to $<0.05 \mathrm{nM}$ (Pyhtila and Rexach 2003). It must be considered that this could be due to Kap60 binding to Nup1 directly, thus contributing to the combined affinity. On the other hand, the presence of the IBB domain of Kap60 (the portion that binds to Kap95) was shown to have no effect on the affinity between Imp $\beta$ and p62 (Ben-Efraim and Gerace 2001) or to decrease it by $\sim 40$-fold (Lott et al. 2010). Thus, the affinity of the interactions between Kaps and FG nups that enable selective transport through the NPC are not entirely clear.

However, there is a problem with affinities measured in vitro, even beyond the contradictory observations: These affinities are all too tight to reconcile with the rapid transport observed in vivo. The total concentration of transport factors in living cells is $\sim 20 \mu \mathrm{M}$ (Ghaemmaghami et al. 2003; Pyhtila and Rexach 2003; Timney et al. 2006; Paradise et al. 2007). This concentration is nearly 1000-fold higher than the measured in vitro affinities between Kaps and FG nups, suggesting that FG domains in living cells are completely saturated with transport factors (Peters 2009a). This high concentration of Kaps may interfere with inter- and intra-FG interactions, impeding the formation of a saturated hydrogel of FG nups. Moreover, transport through the NPC is fast, with single-molecule fluorescence measurements showing Kap-cargo complexes crossing the NPC in milliseconds (Yang et al. 2004; Kubitscheck et al. 2005). Bulk measurement of protein import indicated that thousands of transport events occur through each NPC every second (Ribbeck and Gorlich 2001). On the basis of observed transport kinetics, the affinity between Kaps and FG nups was predicted to be transient and weak, with dissociation constants on the order of several millimolar (Macara 2001). This is up to six orders of magnitude weaker than the measured affinities, which are often in the nanomolar range or tighter (Ben-Efraim and Gerace 2001; Bayliss et al. 2002b; Gilchrist et al. 2002; Pyhtila and Rexach 2003; Lott et al. 2010). This discrepancy needs to be addressed if we are to understand how Kap/FG nup binding enables selective transport through the NPC.

\section{Nonspecific Competition}

To a first approximation, most protein-protein interactions involve the association of two roughly globular proteins, each with single chemically complex and compatible binding sites. These interactions are typically unaffected by nonspecific binders because the nonspecific proteins cannot fit into the structured binding sites. As described above, Kaps and, in particular, FG nups can both move between multiple conformations, and each has multiple simple binding sites that can change their position relative to one another. The flexibility of these proteins and the mul- 
titude of binding sites tremendously increase their potential to interact nonspecifically with bulk proteins in the cell. When monitoring nuclear import in living yeast, accumulation of transported cargo was observed to be much slower than expected (Smith et al. 2002; Timney et al. 2006) based on the speed of intracellular diffusion (Riddick and Macara 2005) and the short residence times of import complexes at the NPC (Yang et al. 2004; Kubitscheck et al. 2005). This led to the hypothesis that the Kaps and cargoes spend much of their time interacting with bulk proteins in the cytoplasm (Timney et al. 2006). It was proposed that the ratelimiting step of the transport cycle is not crossing the NPC itself but is instead the formation of the Kap-cargo complex in the crowded environment of the living cell (Timney et al. 2006). In support of this idea, Kaps have been shown by fluorescence correlation spectroscopy to diffuse through the cytoplasm at a slower pace than would be expected for a freely moving macromolecule, leading to the conclusion that Kaps spend a significant amount of time interacting with immobile components of the cytoplasm (Paradise et al. 2007). Thus, competition between specific (cargo) and nonspecific (bulk cytoplasmic components) binding for Kaps has been seen to have a key role in transport in living cells. The concentration of bulk proteins within a living cell has been estimated to be on the order of $\sim 100 \mathrm{mg} / \mathrm{mL}$ (Zimmerman and Trach 1991; Zimmerman and Minton 1993). Assuming an average molecular weight of $50 \mathrm{kDa}$ for cellular protein, this gives a total concentration of $\sim 2-$ $\mathrm{mm}$ total protein. The $14 \mathrm{Kaps}$ in yeast have a total concentration of, at most, $20 \mu \mathrm{M}$ (Ghaemmaghami et al. 2003; Pyhtila and Rexach 2003; Timney et al. 2006; Paradise et al. 2007) and thus together constitute less than $1 / 100$ th of the total protein concentration. Therefore, even if noncargo molecules bind FG nups only weakly, these nonspecific proteins are at a high enough concentration to provide very significant competition for binding sites within the NPC.

The nuclear transport system, however, seems to have turned this potential problem to its advantage. Competi- tion between specific and nonspecific binders has been shown theoretically (Zilman et al. 2007, 2010) and experimentally (Jovanovic-Talisman et al. 2009) to enhance the selectivity of a functionalized membrane. In these analyses, a protein that only weakly interacts with the FG nups can go through an FG nup-functionalized pore without much hindrance. However, when facing the pore in the presence of a strong binder, the transport of the weakly binding protein is effectively stopped. This is thought to be caused by competition for the limited number of binding sites and physical space within the functionalized pore, with the more strongly binding protein outcompeting the weaker one (Fig. 6). The implication here is that the movement of transport factors across the NPC not only carries cargoes but also helps to maintain the selectivity of the NPC. Whether loaded with cargo or free, transport factors act as bouncers at the gate, competitively sweeping out molecules from the NPC that do not belong and preventing their leakage across the NE. Leakage of nonspecific molecules into the central channel from the nucleoplasm and cytoplasm would mean that this competition effect occurs throughout the channel length, keeping the competition effect up and the effective affinity of the transport factors low enough for rapid exchange and movement (although few, if any, nonspecific molecules from either side would make it all the way across the channel). Taken together, this suggests that the barrier function of the NPC is maintained by an optimal flux of transport factors moving back and forth across it.

If an optimal flux of transport factors is required to maintain selective transport through the NPC, it might be expected that the total flux of transport factors across the NE would correlate with the number of NPCs. For example, a quiescent cell would require less nucleocytoplasmic transport than a growing cell, so the quiescent cell would be expected to have few NPCs, whereas an actively growing cell would require many. This direct relationship between NPC number and metabolic activity has been observed in living cells (Maul et al. 1972, 1980).
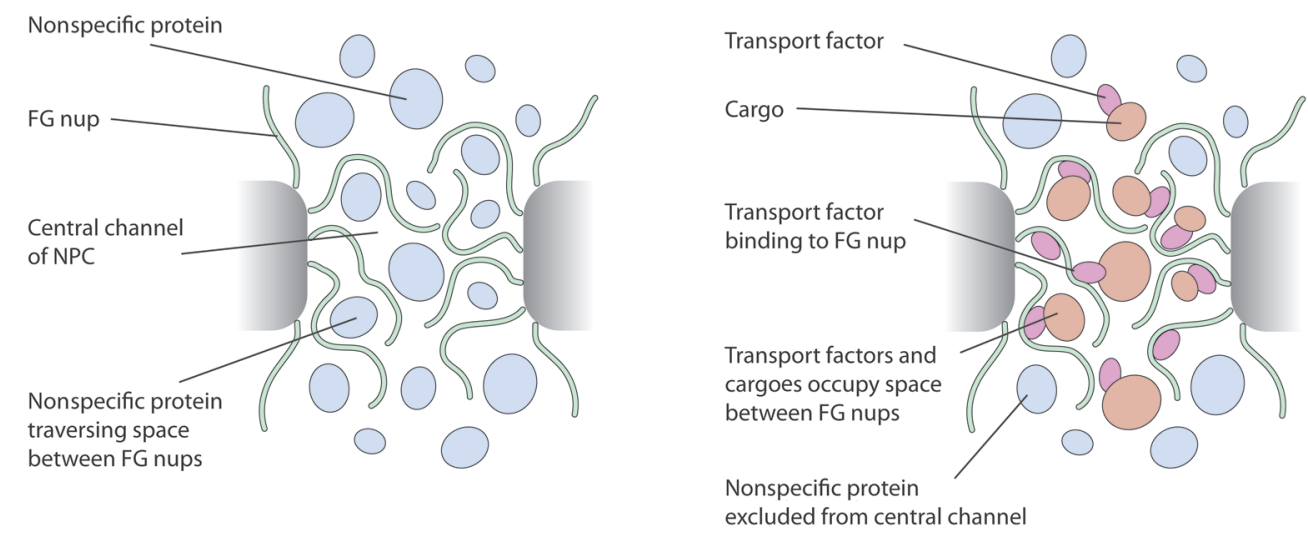

Figure 6. Competition for space within the NPC increases selectivity. (Left) When a nonbinding molecule (blue) faces an FG nup-lined pore alone, it is able to cross. (Right) However, the nonbinding molecule is inhibited from crossing when in the presence of a binding molecule (pink); proteins that can bind to FG nups (pink) remain at the channel longer than molecules that do not bind FG nups (blue), and these binding molecules thus occupy space within the channel, preventing nonbinding molecules from crossing. 
The ability of Kaps to carry large cargoes through the NPC (Pante and Kann 2002) may also act to increase transport selectivity. The bulky cargoes occupy physical space within the pore as they are carried through by Kaps (Fig. 6 ). If we assume that $\sim 1000$ specific transport events occur through each NPC every second (Ribbeck and Gorlich 2001) and that each Kap/cargo complex remains in the NPC for 30 msec (Yang et al. 2004; Kubitscheck et al. 2005), this means that 30 Kap-cargo complexes should be in each NPC at any one time. Kaps are $\sim 8 \mathrm{~nm}$ in diameter (Chook and Blobel 1999; Bayliss et al. 2000b, 2002b; Cansizoglu and Chook 2007), thus 30 of these globular Kaps would occupy $\sim 8000 \mathrm{~nm}^{3}$. Cargoes can range in size from the $\sim 25 \mathrm{kDa}(\sim 0.4-\mathrm{nm}$ diameter) Ran GTPase (Moore and Blobel 1998; Paschal and Gerace 1995; Scheffzek et al. 2002; Partridge and Schwartz 2009) to 2 MDa ( 39-nm diameter) ribosomal subunits (Pante and Kann 2002). If we assume that the average cargo diameter is $10 \mathrm{~nm}, 30 \mathrm{such}$ cargoes would occupy $\sim 16,000 \mathrm{~nm}^{3}$. FG nups themselves would occupy a volume of $\sim 6500 \mathrm{~nm}^{3}$ in the yeast NPC (Tu and Musser 2011). Thus, the 30 Kap-cargo complexes that simultaneously cross each NPC and the FG nups would occupy a combined volume of $\sim 30,500 \mathrm{~nm}^{3}$. Given the dimensions of the central channel as observed by EM (Yang et al. 1998; Kiseleva et al. 2003), the channel is expected to have a total volume of $\sim 40,000 \mathrm{~nm}^{3}$. Therefore, based on these estimates, $\sim 75 \%$ of the pore volume could be occupied at any one time by FG nups and specifically transported Kap-cargo complexes. These large macromolecules and complexes crossing the pore may physically prevent noncargo molecules from entering, in large part simply by filling up so much of the available volume (Fig. 6). Indeed, competition between adjacent FG repeat regions in the channel may further enhance these effects.

\section{Connecting NPC Structure with Transport Mechanism}

It is agreed that specifically transported molecules can pass through the NPC because they can bind to FG nups, but the importance of the detailed organization of the FG nups within the NPC remains unclear. An affinity gradient was proposed in which Kaps move from low- to high-affinity binding sites as they cross from the cytoplasm to the nucleus (Rexach and Blobel 1995; Ben-Efraim and Gerace 2001; Pyhtila and Rexach 2003). Although an asymmetric high-affinity binding step may enhance transport in at least some cases (Blobel 1995; Nachury and Weis 1999; Allen et al. 2000; Bednenko et al. 2003; Rout et al. 2003), it cannot be essential because all asymmetric FG domains can be deleted (Strawn et al. 2004) or switched to the opposite side of the NPC (Zeitler and Weis, 2004), and transport is largely unaltered. In addition, the spatial distribution of binding sites along a channel only weakly affected rate of transport through the channel in a mathematical model (Zilman et al. 2007). It has also been proposed that both the entrance and exit of the pore must contain binding sites for rapid selective transport to occur, because if there are no binding sites at one end, the entropic barrier at that end will impede transport (Nielsen et al. 2006).

\section{NPC as Scaffold for Other Processes}

In addition to their role in nucleocytoplasmic transport, FG nups such as yeast Nup42 and Nup159 have been shown to contain specific binding motifs for proteins that have accessory roles in transport and are involved in recruitment of other proteins to the NPC, such as RNA processing factors Dbp5 and Gle1 (Stewart 2007b; Carmody and Wente 2009; Strambio-De-Castillia et al. 2010). Metazoan Nup358 recruits mRNA export factor Nxf1 (Forler et al. 2004). These binding events create a high local concentration of proteins involved in RNA processing at the NPC, ensuring that RNP export and translation are correctly coupled (Stewart, 2007b). Thus, FG nups seem to function by recruiting proteins so that they can obtain the high local concentration needed, creating a dynamic cloud enriched in transport factors. The FG nups, therefore, may not only comprise the selective gate but also actively facilitate transport by recruiting the necessary players.

As stated above, many peripheral nups are highly mobile and spend significant amounts of time in the nucleoplasm and cytoplasm. Several of these mobile FG and non-FG nups in Drosophila have been shown to bind to specific sites on the genome, away from the NPCs (Capelson et al. 2010). These mobile nups are involved in regulating transcription of certain target genes (Capelson et al. 2010). Perhaps one mechanism by which these mobile nups perform this function is by recruiting other transcription factors, creating a cloud of high local concentration of these proteins at appropriate sites along the genome, analogous to the way these proteins may function in the NPC.

\section{CONCLUSIONS}

Although much progress has been made in our understanding of how the simple structure of the NPC mediates selective transport across the NE, many questions still remain. We are still learning how the natively unfolded FG nups prevent the passage of inert proteins while facilitating the passage of binding proteins. The importance of charge in the level of inter- and intra-FG repeat interactions has begun to be explored, but the physical properties of the FG nup barrier remain unclear. Transport factor binding to FG nups has been shown to be affected by nonspecific competition, and this may explain the apparent discrepancy between tight affinities measured in vitro and very rapid transport observed in vivo. Thus, FG nups cannot be studied in isolation - their interactions with other FG nups and with other proteins in their environment, both specific and nonspecific, must not be ignored.

\section{ACKNOWLEDGMENTS}

The authors gratefully acknowledge Loren Hough, Roxana Mironska, Tijana Jovanovic-Talisman, and Benjamin Timney for critical reviewing the manuscript. We are indebted to Anton Zilman for numerous discussions clarifying the physics of transport through a small hole and to Daniel Russel for creating the amino acid sequence models in Figure 4. J.T.-N. was supported by a Howard Hughes Medical 
Institute Predoctoral Fellowship, and M.P.R. is supported by National Institutes of Health grants GM071329, GM062427, and RR022220.

\section{REFERENCES}

Adam E, Adam S. 1994. Identification of cytosolic factors required for nuclear location sequence-mediated binding to the nuclear envelope. J Cell Biol 125: 547-555.

Ader C, Frey S, Maas W, Schmidt HB, Gorlich D, Baldus M. 2010. Amyloid-like interactions within nucleoporin FG hydrogels. Proc Natl Acad Sci 107: 6281-6285.

Aitchison JD, Blobel G, Rout MP. 1996. Kap104p: A karyopherin involved in the nuclear transport of messenger RNA binding proteins. Science 274: 624-627.

Akey CW. 1989. Interactions and structure of the nuclear pore complex revealed by cryo-electron microscopy. J Cell Biol 109: 955-970.

Akey CW. 1990. Visualization of transport-related configurations of the nuclear pore transporter. Biophys J 58: $341-355$.

Akey CW, Radermacher M. 1993. Architecture of the Xenopus nuclear pore complex revealed by three-dimensional cryo-electron microscopy. J Cell Biol 122: 1-19.

Alber F, Dokudovskaya S, Veenhoff L, Zang W, Kipper J, Devos D, Suprapto A, Karni-Schmidt O, Williams R, Chait B, et al. 2007a. Determining the architectures of macromolecular assemblies. Nature 450: 683-694.

Alber F, Dokudovskaya S, Veenhoff L, Zhang W, Kipper J, Devos D, Suprapto A, Karni-Schmidt O, Williams R, Chait B, et al. 2007b. The molecular architecture of the nuclear pore complex. Nature 450: 695-701.

Allen TD, Cronshaw JM, Bagley S, Kiseleva E, Goldberg MW. 2000. The nuclear pore complex: Mediator of translocation between nucleus and cytoplasm. J Cell Sci 113: 1651-1659.

Allen N, Huang L, Burlingame A, Rexach M. 2001. Proteomic analysis of nucleoporin interacting proteins. J Biol Chem 276: 29268-29274.

Arnold RJ, Reilly JP. 1999. Observation of Escherichia coli ribosomal proteins and their posttranslational modifications by mass spectrometry. Anal Biochem 269: 105-112.

Arts GJ, Fornerod M, Mattaj IW. 1998. Identification of a nuclear export receptor for tRNA. Curr Biol 8: 305-314.

Bailer SM, Siniossoglou S, Podtelejnikov A, Hellwig A, Mann M, Hurt E. 1998. Nup116p and nup100p are interchangeable through a conserved motif which constitutes a docking site for the mRNA transport factor gle2p. EMBO J 17: 1107-1119.

Bayliss R, Ribbeck K, Akin D, Kent HM, Feldherr CM, Gorlich D, Stewart M. 1999. Interaction between NTF2 and xFxFG-containing nucleoporins is required to mediate nuclear import of RanGDP. J Mol Biol 293: 579-593.

Bayliss R, Kent HM, Corbett AH, Stewart M. 2000a. Crystallization and initial X-ray diffraction characterization of complexes of FxFG nucleoporin repeats with nuclear transport factors. $J$ Struct Biol 131: 240-247.

Bayliss R, Littlewood T, Stewart M. 2000b. Structural basis for the interaction between FxFG nucleoporin repeats and importin- $\beta$ in nuclear trafficking. Cell 102: 99-108.

Bayliss R, Leung SW, Baker RP, Quimby BB, Corbett AH, Stewart M. 2002a. Structural basis for the interaction between NTF2 and nucleoporin FxFG repeats. EMBO J 21: 2843-2853.

Bayliss R, Littlewood T, Strawn LA, Wente SR, Stewart M. 2002 b. GLFG and FxFG nucleoporins bind to overlapping sites on importin- $\beta$. J Biol Chem 277: 50597-50606.

Beck M, Forster F, Ecke M, Plitzko JM, Melchior F, Gerisch G, Baumeister W, Medalia O. 2004. Nuclear pore complex structure and dynamics revealed by cryoelectron tomography. Science 306: 1387-1390.

Beck M, Lucic V, Forster F, Baumeister W, Medalia O. 2007. Snapshots of nuclear pore complexes in action captured by cryo-electron tomography. Nature 449: 611-615.

Bednenko J, Cingolani G, Gerace L. 2003. Nucleocytoplasmic transport: Navigating the channel. Traffic 4: 127-135.
Belden WJ, Barlowe C. 2001. Purification of functional Sec13pSec31p complex, a subunit of COPII coat. Methods Enzymol 329: 438-443.

Ben-Efraim I, Gerace L. 2001. Gradient of increasing affinity of importin $\beta$ for nucleoporins along the pathway of nuclear import. J Cell Biol 152: 411-417.

Berezhkovskii AM, Bezrukov SM. 2005. Optimizing transport of metabolites through large channels: Molecular sieves with and without binding. Biophys $J$ 88: L17-L19.

Berezhkovskii, AM, Pustovoit, MA, and Bezrukov, SM. 2002. Channel-facilitated membrane transport: Transit probability and interaction with the channel. J Chem Phys 116: 6216-6220.

Berg HC. 1993. Random walks in biology, expanded ed. Princeton University Press, Princeton, NJ.

Berke IC, Boehmer T, Blobel G, Schwartz, TU. 2004. Structural and functional analysis of Nup133 domains reveals modular building blocks of the nuclear pore complex. J Cell Biol 167: 591-597.

Beverley SM. 2003. Protozomics: Trypanosomatid parasite genetics comes of age. Nat Rev Genet 4: 11-19.

Bischoff FR, Krebber H, Smirnova E, Dong W, Ponstingl H. 1995. Co-activation of RanGTPase and inhibition of GTP dissociation by Ran-GTP binding protein RanBP1. EMBO J 14: 705-715.

Blobel G. 1980. Intracellular protein topogenesis. Proc Natl Acad Sci 77: 1496-1500.

Blobel G. 1995. Unidirectional and bidirectional protein traffic across membranes. Cold Spring Harbor Symp Quant Biol 60: $1-10$.

Boehm M, Bonifacino JS. 2001. Adaptins: The final recount. $\mathrm{Mol}$ Biol Cell 12: 2907-2920.

Boehmer T, Jeudy S, Berke IC, Schwartz TU. 2008. Structural and functional studies of Nup107/Nup133 interaction and its implications for the architecture of the nuclear pore complex. Mol Cell 30: 721-731.

Bonifacino JS, Glick BS. 2004. The mechanisms of vesicle budding and fusion. Cell 116: 153-166.

Bradatsch B, Katahira J, Kowalinski E, Bange G, Yao W, Sekimoto T, Baumgartel V, Boese G, Bassler J, Wild K, et al. 2007. Arx1 functions as an unorthodox nuclear export receptor for the $60 \mathrm{~S}$ preribosomal subunit. Mol Cell 27: 767-779.

Bright JN, Woolf TB, Hoh JH. 2001. Predicting properties of intrinsically unstructured proteins. Prog Biophys Mol Biol 76: 131-173.

Brown HG, Hoh JH. 1997. Entropic exclusion by neurofilament sidearms: A mechanism for maintaining interfilament spacing. Biochemistry 36: 15035-15040.

Brown CJ, Takayama S, Campen AM, Vise P, Marshall TW, Oldfield CJ, Williams CJ, Dunker AK. 2002. Evolutionary rate heterogeneity in proteins with long disordered regions. J Mol Evol 55: 104-110.

Bullock TL, Clarkson WD, Kent HM, Stewart M. 1996. The 1.6 resolution crystal structure of nuclear transport factor 2 (NTF2). J Mol Biol 260: 422-431.

Cansizoglu AE, Chook YM. 2007. Conformational heterogeneity of karyopherin $\beta 2$ is segmental. Structure 15: 1431-1441.

Capelson M, Liang Y, Schulte R, Mair W, Wagner U, Hetzer MW. 2010. Chromatin-bound nuclear pore components regulate gene expression in higher eukaryotes. Cell 140: 372-383.

Carmody SR, Wente SR. 2009. mRNA nuclear export at a glance. J Cell Sci 122: 1933-1937.

Caspi Y, Zbaida D, Cohen H, Elbaum M. 2008. Synthetic mimic of selective transport through the nuclear pore complex. Nano Lett 8: 3728-3734.

Catimel B, Teh T, Fontes MR, Jennings IG, Jans DA, Howlett GJ, Nice EC, Kobe B. 2001. Biophysical characterization of interactions involving importin- $\alpha$ during nuclear import. $J$ Biol Chem 276: 34189-34198.

Chook YM, Blobel G. 1999. Structure of the nuclear transport complex karyopherin-ß32-Ran x GppNHp. Nature 399: 230237.

Chook YM, Blobel G. 2001. Karyopherins and nuclear import. Curr Opin Struct Biol 11: 703-715.

Collins BM, McCoy AJ, Kent HM, Evans PR, Owen DJ. 2002. 
Molecular architecture and functional model of the endocytic AP2 complex. Cell 109: 523-535.

Colwell LJ, Brenner MP, Ribbeck K. 2010. Charge as a selection criterion for translocation through the nuclear pore complex. PLoS Comput Biol 6: e1000747.

Conti E, Kuriyan J. 2000. Crystallographic analysis of the specific yet versatile recognition of distinct nuclear localization signals by karyopherin $\alpha$. Structure 8: 329-338.

Conti E, Izaurralde E. 2001. Nucleocytoplasmic transport enters the atomic age. Curr Opin Cell Biol 13: 310-319.

Conti E, Uy M, Leighton L, Blobel G, Kuriyan J. 1998. Crystallographic analysis of the recognition of a nuclear localization signal by the nuclear import factor karyopherin $\alpha$. Cell 94: 193-204.

Conti E, Muller CW, Stewart M. 2006. Karyopherin flexibility in nucleocytoplasmic transport. Curr Opin Struct Biol 16: 237244.

Cordes VC, Reidenbach S, Rackwitz HR, Franke WW. 1997. Identification of protein $\mathrm{p} 270 / \mathrm{Tpr}$ as a constitutive component of the nuclear pore complex-attached intranuclear filaments. J Cell Biol 136: 515-529.

Cronshaw JM, Krutchinsky AN, Zhang W, Chait BT, Matunis MJ. 2002. Proteomic analysis of the mammalian nuclear pore complex. J Cell Biol 158: 915-927.

D’Angelo MA, Hetzer MW. 2008. Structure, dynamics and function of nuclear pore complexes. Trends Cell Biol 18: 456-466.

D’Angelo MA, Raices M, Panowski SH, Hetzer MW. 2009. Agedependent deterioration of nuclear pore complexes causes a loss of nuclear integrity in postmitotic cells. Cell 136: 284-295.

Davis LI. 1995. The nuclear pore complex. Annu Rev Biochem 64: 865-896.

Debler EW, Ma Y, Seo HS, Hsia KC, Noriega TR, Blobel G, Hoelz A. 2008. A fence-like coat for the nuclear pore membrane. Mol Cell 32: 815-826.

DeGrasse JA, DuBois KN, Devos D, Siegel TN, Sali A, Field MC, Rout MP, Chait BT. 2009. Evidence for a shared nuclear pore complex architecture that is conserved from the last common eukaryotic ancestor. Mol Cell Proteomics 8: 2119-2130.

Denning D, Rexach M. 2007. Rapid evolution exposes the boundaries of domain structure and function in natively unfolded FG nucleoporins. Mol Cell Proteomics 6: 272-282.

Denning D, Mykytka B, Allen NP, Huang L, Al B, Rexach M. 2001. The nucleoporin Nup60p functions as a Gsp1p-GTP-sensitive tether for Nup2p at the nuclear pore complex. J Cell Biol 154: 937-950.

Denning D, Patel S, Uversky V, Fink A, Rexach M. 2003. Disorder in the nuclear pore complex: The FG repeat regions of nucleoporins are natively unfolded. Proc Natl Acad Sci 100: 24502455.

Devos D, Dokudovskaya S, Alber F, Williams R, Chait BT, Sali A, Rout MP. 2004. Components of coated vesicles and nuclear pore complexes share a common molecular architecture. PLoS Biol 2: e380.

Devos D, Dokudovskaya S, Williams R, Alber F, Eswar N, Chait BT, Rout MP, Sali A. 2006. Simple fold composition and modular architecture of the nuclear pore complex. Proc Natl Acad Sci 103: 2172-2177.

Dingwall C, Robbins J, Dilworth SM, Roberts B, Richardson WD. 1988. The nucleoplasmin nuclear location sequence is larger and more complex than that of SV-40 large T antigen. J Cell Biol 107: 841-849.

Dishinger JF, Kee HL, Jenkins PM, Fan S, Hurd TW, Hammond JW, Truong YN, Margolis B, Martens JR, Verhey KJ. 2010. Ci1iary entry of the kinesin-2 motor KIF17 is regulated by importin- 32 and RanGTP. Nat Cell Biol 12: 703-710.

Doucet CM, Talamas JA, Hetzer MW. 2010. Cell cycle-dependent differences in nuclear pore complex assembly in metazoa. Cell 141: 1030-1041.

Dworetzky SI, Feldherr CM. 1988. Translocation of RNA-coated gold particles through the nuclear pores of oocytes. J Cell Biol 106: $575-584$.

Eisele NB, Frey S, Piehler J, Gorlich D, Richter RP. 2010. Ultrathin nucleoporin phenylalanine-glycine repeat films and their inter- action with nuclear transport receptors. EMBO Rep 11: 366372.

Elad N, Maimon T, Frenkiel-Krispin D, Lim RY, Medalia O. 2009. Structural analysis of the nuclear pore complex by integrated approaches. Curr Opin Struct Biol 19: 226-232.

Evans PR, Owen DJ. 2002. Endocytosis and vesicle trafficking. Curr Opin Struct Biol 12: 814-821.

Fath S, Mancias JD, Bi X, Goldberg J. 2007. Structure and organization of coat proteins in the COPII cage. Cell 129: 1325-1336.

Feldherr C, Akin D, Littlewood T, Stewart M. 2002. The molecular mechanism of translocation through the nuclear pore complex is highly conserved. J Cell Sci 115: 2997-3005.

Feng W, Benko AL, Lee JH, Stanford DR, Hopper AK. 1999. Antagonistic effects of NES and NLS motifs determine $S$. cerevisiae Rnalp subcellular distribution. J Cell Sci 112: 339-347.

Field MC, Dacks JB. 2009. First and last ancestors: Reconstructing evolution of the endomembrane system with ESCRTs, vesicle coat proteins, and nuclear pore complexes. Curr Opin Cell Biol 21: 4-13.

Floer M, Blobel G. 1996. The nuclear transport factor karyopherin $\beta$ binds stoichiometrically to Ran-GTP and inhibits the Ran GTPase activating protein. J Biol Chem 271: 5313-5316.

Floer M, Blobel G, Rexach M. 1997. Disassembly of RanGTPkaryopherin $\beta$ complex, an intermediate in nuclear protein import. J Biol Chem 272: 19538-19546.

Forler D, Rabut G, Ciccarelli FD, Herold A, Kocher T, Niggeweg R, Bork P, Ellenberg J, Izaurralde E. 2004. RanBP2/Nup358 provides a major binding site for NXF1-p15 dimers at the nuclear pore complex and functions in nuclear mRNA export. $\mathrm{Mol}$ Cell Biol 24: 1155-1167.

Frenkiel-Krispin D, Maco B, Aebi U, Medalia O. 2010. Structural analysis of a metazoan nuclear pore complex reveals a fused concentric ring architecture. J Mol Biol 395: 578-586.

Frey S, Gorlich D. 2007. A saturated FG-repeat hydrogel can reproduce the permeability properties of nuclear pore complexes. Cell 130: 512-523.

Frey S, Gorlich D. 2009. FG/FxFG as well as GLFG repeats form a selective permeability barrier with self-healing properties. EMBO J 28: 2554-2567.

Frey S, Richter RP, Gorlich D. 2006. FG-rich repeats of nuclear pore proteins form a three-dimensional meshwork with hydrogel-like properties. Science 314: 815-817.

Fribourg S, Conti E. 2003. Structural similarity in the absence of sequence homology of the messenger RNA export factors Mtr2 and p15. EMBO Rep 4: 699-703.

Fukuhara N, Fernandez E, Ebert J, Conti E, Svergun D. 2004. Conformational variability of nucleo-cytoplasmic transport factors. J Biol Chem 279: 2176-2181.

Gehrke SH, Fisher JP, Palasis M, Lund ME. 1997. Factors determining hydrogel permeability. Ann NY Acad Sci 831: 179-207.

Ghaemmaghami S, Huh WK, Bower K, Howson RW, Belle A, Dephoure N, O'Shea EK, Weissman JS. 2003. Global analysis of protein expression in yeast. Nature 425: 737-741.

Gilchrist D, Rexach M. 2003. Molecular basis for the rapid dissociation of nuclear localization signals from karyopherin $\alpha$ in the nucleoplasm. J Biol Chem 278: 51937-51949.

Gilchrist D, Mykytka B, Rexach M. 2002. Accelerating the rate of disassembly of karyopherin.cargo complexes. J Biol Chem 277: 18161-18172.

Goldfarb D, Gariepy J, Schoolnik G, Kornberg R. 1986. Synthetic peptides as nuclear localization signals. Nature 322: 641-644.

Gorlich D, Prehn S, Laskey RA, Hartmann E. 1994. Isolation of a protein that is essential for the first step of nuclear protein import. Cell 79: 767-778.

Gorlich D, Vogel F, Mills A, Hartmann E, Laskey R. 1995. Distinct functions for the two importin subunits in nuclear protein import. Nature 377: 246-248.

Gorlich D, Pante N, Kutay U, Aebi U, Bischoff FR. 1996. Identification of different roles for RanGDP and RanGTP in nuclear protein import. EMBO J 15: 5584-5594.

Grant RP, Neuhaus D, Stewart M. 2003. Structural basis for the interaction between the Tap/NXF1 UBA domain and FG nucleoporins at 1A resolution. J Mol Biol 326: 849-858. 
Grathwohl P. 1998. Diffusion in natural porous media: Contaminant transport, sorption/desorption and dissolution kinetics. Kluwer Academic, Norwell, MA.

Grünwald D, Singer RH. 2010. In vivo imaging of labelled endogenous $\beta$-actin mRNA during nucleocytoplasmic transport. $\mathrm{Na}$ ture 467: 604-607.

Handa N, Kukimoto-Niino M, Akasaka R, Kishishita S, Murayama $\mathrm{K}$, Terada $\mathrm{T}$, Inoue $\mathrm{M}$, Kigawa $\mathrm{T}$, Kose $\mathrm{S}$, Imamoto N, et al 2006. The crystal structure of mouse Nup35 reveals atypical RNP motifs and novel homodimerization of the RRM domain. J Mol Biol 363: 114-124.

Harel A, Chan RC, Lachish-Zalait A, Zimmerman E, Elbaum M, Forbes DJ. 2003. Importin $\beta$ negatively regulates nuclear membrane fusion and nuclear pore complex assembly. Mol Biol Cell 14: 4387-4396.

Hellmuth K, Lau DM, Bischoff FR, Kunzler M, Hurt E, Simos G. 1998. Yeast Los 1p has properties of an exportin-like nucleocytoplasmic transport factor for tRNA. Mol Cell Biol 18: 63746386.

Hill TL. 1975. Effect of rotation on the diffusion-controlled rate of ligand-protein association. Proc Natl Acad Sci 72: 4918-4922.

Hodel AE, Hodel MR, Griffis ER, Hennig KA, Ratner GA, Xu S, Powers MA. 2002. The three-dimensional structure of the autoproteolytic, nuclear pore-targeting domain of the human nucleoporin Nup98. Mol Cell 10: 347-358.

Hsia KC, Stavropoulos P, Blobel G, Hoelz A. 2007. Architecture of a coat for the nuclear pore membrane. Cell 131: 1313-1326.

Hung NJ, Lo KY, Patel SS, Helmke K, Johnson AW. 2008. Arx1 is a nuclear export receptor for the $60 \mathrm{~S}$ ribosomal subunit in yeast. Mol Biol Cell 19: 735-744.

Hutten S, Walde S, Spillner C, Hauber J, Kehlenbach RH. 2009. The nuclear pore component Nup358 promotes transportin-dependent nuclear import. J Cell Sci 122: 1100-1110.

Iovine MK, Watkins JL, Wente SR. 1995. The GLFG repetitive region of the nucleoporin Nup116p interacts with Kap95p, an essential yeast nuclear import factor. J Cell Biol 131: 1699-1713.

Isgro TA, Schulten K. 2005. Binding dynamics of isolated nucleoporin repeat regions to importin- $\beta$. Structure 13: 1869-1879.

Isgro TA, Schulten K. 2007a. Association of nuclear pore FG-repeat domains to NTF2 import and export complexes. J Mol Biol 366: $330-345$.

Isgro TA, Schulten K. 2007b. Cse1p-binding dynamics reveal a binding pattern for FG-repeat nucleoporins on transport receptors. Structure 15: 977-991.

Izaurralde E, Kutay U, von Kobbe C, Mattaj IW, Gorlich D. 1997. The asymmetric distribution of the constituents of the Ran system is essential for transport into and out of the nucleus. EMBO J 16: 6535-6547.

Jarnik M, Aebi U. 1991. Toward a more complete 3-D structure of the nuclear pore complex. J Struct Biol 107: 291-308.

Jovanovic-Talisman T, Tetenbaum-Novatt J, McKenney AS, Zilman A, Peters R, Rout MP, Chait BT. 2009. Artificial nanopores that mimic the transport selectivity of the nuclear pore complex. Nature 457: 1023-1027.

Kawai T, Saito K, Lee W. 2003. Protein binding to polymer brush, based on ion-exchange, hydrophobic, and affinity interactions. J Chromatogr 790: 131-142.

King MC, Lusk CP, Blobel G. 2006. Karyopherin-mediated import of integral inner nuclear membrane proteins. Nature 442: $1003-$ 1007.

Kirchhausen T. 2000. Three ways to make a vesicle. Nat Rev Mol Cell Biol 1: 187-198.

Kiseleva E, Allen TD, Rutherford S, Bucci M, Wente SR, Goldberg MW. 2003. Yeast nuclear pore complexes have a cytoplasmic ring and internal filaments. J Struct Biol 145: 272-288.

Klebe C, Prinz H, Wittinghofer A, Goody RS. 1995. The kinetic mechanism of Ran-nucleotide exchange catalyzed by RCC1. Biochemistry 34: 12543-12552.

Kohler A, Hurt E. 2007. Exporting RNA from the nucleus to the cytoplasm. Nat Rev Mol Cell Biol 8: 761-773.

Kohli P, Harrell CC, Cao Z, Gasparac R, Tan W, Martin CR. 2004. DNA-functionalized nanotube membranes with single-base mismatch selectivity. Science 305: 984-986.
Kose S, Imamoto N, Tachibana T, Shimamoto T, Yoneda Y. 1997. Ran-unassisted nuclear migration of a 97-kD component of nuclear pore-targeting complex. J Cell Biol 139: 841-849.

Kosova B, Pante N, Rollenhagen C, Podtelejnikov A, Mann M, Aebi U, Hurt E. 2000. Mlp2p, a component of nuclear pore attached intranuclear filaments, associates with nic96p. J Biol Chem 275: 343-350.

Kosugi S, Hasebe M, Tomita M, Yanagawa H. 2008. Nuclear export signal consensus sequences defined using a localizationbased yeast selection system. Traffic 9: 2053-2062.

Kubitscheck U, Grunwald D, Hoekstra A, Rohleder D, Kues T, Siebrasse JP, Peters R. 2005. Nuclear transport of single molecules: Dwell times at the nuclear pore complex. J Cell Biol 168: 233-243.

Kutay U, Lipowsky G, Izaurralde E, Bischoff FR, Schwarzmaier P, Hartmann E, Gorlich D. 1998. Identification of a tRNA-specific nuclear export receptor. Mol Cell 1: 359-369.

Lakshmi BB, Martin CR. 1997. Enantioseparation using apoenzymes immobilized in a porous polymeric membrane. Nature 388: $758-760$.

Lange A, Mills RE, Lange CJ, Stewart M, Devine SE, Corbett AH. 2007. Classical nuclear localization signals: Definition, function, and interaction with importin $\alpha$. J Biol Chem 282: $5101-$ 5105.

Lange A, Mills RE, Devine SE, Corbett AH. 2008. A PY-NLS nuclear targeting signal is required for nuclear localization and function of the Saccharomyces cerevisiae mRNA-binding protein Hrp1. J Biol Chem 283: 12926-12934.

Lee DC, Aitchison JD. 1999. Kap104p-mediated nuclear import. Nuclear localization signals in mRNA-binding proteins and the role of Ran and Rna. J Biol Chem 274: 29031-29037.

Lee C, Goldberg J. 2010. Structure of coatomer cage proteins and the relationship among COPI, COPII, and clathrin vesicle coats. Cell 142: 123-132.

Lee SB, Mitchell DT, Trofin L, Nevanen TK, Soderlund H, Martin CR. 2002. Antibody-based bio-nanotube membranes for enantiomeric drug separations. Science 296: 2198-2200.

Lee BJ, Cansizoglu AE, Suel KE, Louis TH, Zhang Z, Chook, YM. 2006. Rules for nuclear localization sequence recognition by karyopherin $\beta$ 2. Cell 126: 543-558.

Leksa NC, Brohawn SG, Schwartz TU. 2009. The structure of the scaffold nucleoporin Nup120 reveals a new and unexpected domain architecture. Structure 17: 1082-1091.

Leslie DM, Grill B, Rout MP, Wozniak RW, Aitchison JD. 2002. Kap121p-mediated nuclear import is required for mating and cellular differentiation in yeast. Mol Cell Biol 22: 2544-2555.

Leslie DM, Zhang W, Timney BL, Chait BT, Rout MP, Wozniak RW, Aitchison JD. 2004. Characterization of karyopherin cargoes reveals unique mechanisms of Kap121p-mediated nuclear import. Mol Cell Biol 24: 8487-8503.

Lim RY, Deng J. 2009. Interaction forces and reversible collapse of a polymer brush-gated nanopore. ACS Nano 3: 2911-2918.

Lim R, Huang N, Köser J, Deng J, Lau K, Schwarz-Herion K, Fahrenkrog B, Aebi U. 2006. Flexible phenylalanine-glycine nucleoporins as entropic barriers to nucleocytoplasmic transport. Proc Natl Acad Sci 103: 9512-9517.

Lim RY, Fahrenkrog B, Koser J, Schwarz-Herion K, Deng J, Aebi U. 2007a. Nanomechanical basis of selective gating by the nuclear pore complex. Science 318: 640-643.

Lim RY, Koser J, Huang NP, Schwarz-Herion K, Aebi U. 2007 b. Nanomechanical interactions of phenylalanine-glycine nucleoporins studied by single molecule force-volume spectroscopy. J Struct Biol 159: 277-289.

Lim RY, Aebi U, Fahrenkrog B. 2008a. Towards reconciling structure and function in the nuclear pore complex. Histochem Cell Biol 129: 105-116.

Lim RY, Ullman KS, Fahrenkrog B. 2008b. Biology and biophysics of the nuclear pore complex and its components. Int Rev Cell Mol Biol 267: 299-342.

Lipowsky G, Bischoff FR, Izaurralde E, Kutay U, Schafer S, Gross HJ, Beier H, Gorlich D. 1999. Coordination of tRNA nuclear export with processing of tRNA. RNA 5: 539-549.

Liu SM, Stewart M. 2005. Structural basis for the high-affinity 
binding of nucleoporin Nup1p to the Saccharomyces cerevisiae importin- $\beta$ homologue, Kap95p. J Mol Biol 349: 515-525.

Lott K, Bhardwaj A, Mitrousis G, Pante N, Cingolani G. 2010. The importin $\beta$ binding domain modulates the avidity of importin $\beta$ for the nuclear pore complex. J Biol Chem 285: 13769-13780.

Lowe AR, Siegel JJ, Kalab P, Siu M, Weis K, Liphardt JT. 2010. Selectivity mechanism of the nuclear pore complex characterized by single cargo tracking. Nature 467: 600-603.

Lund E, Dahlberg JE. 1998. Proofreading and aminoacylation of tRNAs before export from the nucleus. Science 282: 2082-2085.

Macara IG. 2001. Transport into and out of the nucleus. Microbiol Mol Biol Rev 65: 570-594.

Madrid AS, Weis K. 2006. Nuclear transport is becoming crystal clear. Chromosoma 115: 98-109.

Marelli M, Aitchison JD, Wozniak RW. 1998. Specific binding of the karyopherin Kap121p to a subunit of the nuclear pore complex containing Nup53p, Nup59p, and Nup170p. J Cell Biol 143: 1813-1830.

Matsuura Y, Stewart M. 2004. Structural basis for the assembly of a nuclear export complex. Nature 432: 872-877.

Maul GG, Maul HM, Scogna JE, Lieberman MW, Stein GS, Hsu BY, Borun TW. 1972. Time sequence of nuclear pore formation in phytohemagglutinin-stimulated lymphocytes and in $\mathrm{HeLa}$ cells during the cell cycle. J Cell Biol 55: 433-447.

Maul GG, Deaven LL, Freed JJ, Campbell GL, Becak W. 1980. Investigation of the determinants of nuclear pore number. $C y$ togenet Cell Genet 26: 175-190.

McLane LM, Pulliam KF, Devine SE, Corbett AH. 2008. The Ty1 integrase protein can exploit the classical nuclear protein import machinery for entry into the nucleus. Nucleic Acids Res 36: 4317-4326.

Melcak I, Hoelz A, Blobel G. 2007. Structure of Nup58/45 suggests flexible nuclear pore diameter by intermolecular sliding. Science 315: 1729-1732.

Miao L, Schulten K. 2009. Transport-related structures and processes of the nuclear pore complex studied through molecular dynamics. Structure 17: 449-459.

Minakhina S, Myers R, Druzhinina M, Steward R. 2005. Crosstalk between the actin cytoskeleton and Ran-mediated nuclear transport. BMC Cell Biol 6: 32.

Moore MS, Blobel G. 1992. The two steps of nuclear import, targeting to the nuclear envelope and translocation through the nuclear pore, require different cytosolic factors. Cell 69: 939-950.

Moore MS, Blobel G. 1994. Purification of a Ran-interacting protein that is required for protein import into the nucleus. Proc Natl Acad Sci 91: 10212-10216.

Morrison J, Yang JC, Stewart M, Neuhaus D. 2003. Solution NMR study of the interaction between NTF2 and nucleoporin FxFG repeats. J Mol Biol 333: 587-603.

Mosammaparast N, Pemberton LF. 2004. Karyopherins: From nuclear-transport mediators to nuclear-function regulators. Trends Cell Biol 14: 547-556.

Nachury MV, Weis K. 1999. The direction of transport through the nuclear pore can be inverted. Proc Natl Acad Sci 96: 9622-9627.

Nagy V, Hsia KC, Debler EW, Kampmann M, Davenport AM, Blobel G, Hoelz A. 2009. Structure of a trimeric nucleoporin complex reveals alternate oligomerization states. Proc Natl Acad Sci 106: 17693-17698.

Naim B, Zbaida D, Dagan S, Kapon R, Reich Z. 2009. Cargo surface hydrophobicity is sufficient to overcome the nuclear pore complex selectivity barrier. EMBO J 28: 2697-2705.

Nakielny S, Dreyfuss G. 1998. Import and export of the nuclear protein import receptor transportin by a mechanism independent of GTP hydrolysis. Curr Biol 8: 89-95.

Napetschnig J, Blobel G, Hoelz A. 2007. Crystal structure of the N-terminal domain of the human protooncogene Nup214/CAN. Proc Natl Acad Sci 104: 1783-1788.

Napetschnig J, Kassube SA, Debler EW, Wong RW, Blobel G, Hoelz A. 2009. Structural and functional analysis of the interaction between the nucleoporin Nup214 and the DEAD-box helicase Ddx19. Proc Natl Acad Sci 106: 3089-3094.

Nielsen B, Jeppesen C, Ipsen JH. 2006. Managing free-energy barriers in nuclear pore transport. J Biol Phys 32: 465-472.
Ohtsubo M, Okazaki H, Nishimoto T. 1989. The RCC1 protein, a regulator for the onset of chromosome condensation locates in the nucleus and binds to DNA. J Cell Biol 109: 1389-1397.

Onischenko E, Stanton LH, Madrid AS, Kieselbach T, Weis K. 2009. Role of the Ndc1 interaction network in yeast nuclear pore complex assembly and maintenance. J Cell Biol 185: 475491.

Ossareh-Nazari B, Bachelerie F, Dargemont C. 1997. Evidence for a role of CRM1 in signal-mediated nuclear protein export. Science 278: 141-144.

Pante N, Kann M. 2002. Nuclear pore complex is able to transport macromolecules with diameters of about $39 \mathrm{~nm}$. Mol Biol Cell 13: 425-434.

Paradise A, Levin MK, Korza G, Carson JH. 2007. Significant proportions of nuclear transport proteins with reduced intracellular mobilities resolved by fluorescence correlation spectroscopy. $J$ Mol Biol 365: 50-65.

Partridge JR, Schwartz TU. 2009. Crystallographic and biochemical analysis of the Ran-binding zinc finger domain. J Mol Biol 391: 375-389.

Paschal BM, Gerace L. 1995. Identification of NTF2, a cytosolic factor for nuclear import that interacts with nuclear pore complex protein p62. J Cell Biol 129: 925-937.

Patel SS, Rexach MF. 2008. Discovering novel interactions at the nuclear pore complex using bead halo: A rapid method for detecting molecular interactions of high and low affinity at equilibrium. Mol Cell Proteomics 7: 121-131.

Patel SS, Belmont BJ, Sante JM, Rexach MF. 2007. Natively unfolded nucleoporins gate protein diffusion across the nuclear pore complex. Cell 129: 83-96.

Peleg O, Lim RY. 2010. Converging on the function of intrinsically disordered nucleoporins in the nuclear pore complex. Biol Chem 391: 719-730.

Peters R. 2005. Translocation through the nuclear pore complex: Selectivity and speed by reduction-of-dimensionality. Traffic 6 : 421-427.

Peters R. 2009a. Functionalization of a nanopore: The nuclear pore complex paradigm. Biochim Biophys Acta 1793: 1533-1539.

Peters R. 2009b. Translocation through the nuclear pore: Kaps pave the way. Bioessays 31: 466-477.

Purcell EM. 1977. Life at low Reynolds number. Am J Phys 45: $3-11$.

Pyhtila B, Rexach M. 2003. A gradient of affinity for the karyopherin Kap95p along the yeast nuclear pore complex. J Biol Chem 278: 42699-42709.

Radu A, Blobel G, Moore M. 1995a. Identification of a protein complex that is required for nuclear-protein import and mediates docking of import substrate to distinct nucleoporins. Proc Natl Acad Sci 92: 1769-1773.

Radu A, Moore M, Blobel G. 1995b. The peptide repeat domain of nucleoporin Nup98 functions as a docking site in transport across the nuclear-pore complex. Cell 81: 215-222.

Reichelt R, Holzenburg A, Buhle EL Jr, Jarnik M, Engel A, Aebi U. 1990. Correlation between structure and mass distribution of the nuclear pore complex and of distinct pore complex components. J Cell Biol 110: 883-894.

Rexach M, Blobel G. 1995. Protein import into nuclei: Association and dissociation reactions involving transport substrate, transport factors, and nucleoporins. Cell 83: 683-692.

Ribbeck K, Gorlich D. 2001. Kinetic analysis of translocation through nuclear pore complexes. EMBO J 20: 1320-1330.

Ribbeck K, Gorlich D. 2002. The permeability barrier of nuclear pore complexes appears to operate via hydrophobic exclusion. EMBO J 21: 2664-2671.

Ribbeck K, Lipowsky G, Kent HM, Stewart M, Gorlich D. 1998. NTF2 mediates nuclear import of Ran. EMBO J 17: 65876598.

Richards SA, Lounsbury KM, Carey KL, Macara IG. 1996. A nuclear export signal is essential for the cytosolic localization of the Ran binding protein, RanBP1. J Cell Biol 134: 1157-1168.

Riddick G, Macara IG. 2005. A systems analysis of importin- $\alpha-\beta$ mediated nuclear protein import. J Cell Biol 168: 1027-1038.

Robinson MA, Park S, Sun ZY, Silver PA, Wagner G, Hogle JM. 
2005. Multiple conformations in the ligand-binding site of the yeast nuclear pore-targeting domain of Nup116p. J Biol Chem 280: 35723-35732.

Rout MP, Blobel G. 1993. Isolation of the yeast nuclear pore complex. J Cell Biol 123: 771-783.

Rout MP, Field MC. 2001. Isolation and characterization of subnuclear compartments from Trypanosoma brucei. Identification of a major repetitive nuclear lamina component. $J$ Biol Chem 276: $38261-38271$

Rout MP, Wente SR. 1994. Pores for thought: Nuclear pore complex proteins. Trends Cell Biol 4: 357-365.

Rout MP, Aitchison JD, Suprapto A, Hjertaas K, Zhao Y, Chait BT. 2000. The yeast nuclear pore complex: Composition, architecture, and transport mechanism. J Cell Biol 148: 635-651.

Rout MP, Aitchison JD, Magnasco MO, Chait BT. 2003. Virtual gating and nuclear transport: The hole picture. Trends Cell Biol 13: $622-628$.

Salama NR, Chuang JS, Schekman RW. 1997. Sec31 encodes an essential component of the COPII coat required for transport vesicle budding from the endoplasmic reticulum. Mol Biol Cell 8: 205-217.

Sampathkumar P, Ozyurt SA, Do J, Bain KT, Dickey M, Rodgers LA, Gheyi T, Sali A, Kim SJ, Phillips J, et al. 2010. Structures of the autoproteolytic domain from the Saccharomyces cerevisiae nuclear pore complex component, Nup145. Proteins 78 : 1992-1998.

Sarkar S, Hopper AK. 1998. tRNA nuclear export in Saccharomyces cerevisiae: In situ hybridization analysis. Mol Biol Cell 9: 3041-3055.

Scheffzek K, Klebe C, Fritz-Wolf K, Kabsch W, Wittinghofer A. 2002. Crystal structure of the nuclear Ras-related protein Ran in its GDP-bound form. Nature 374: 378-381.

Scheifele LZ, Ryan EP, Parent LJ. 2005. Detailed mapping of the nuclear export signal in the Rous sarcoma virus Gag protein. $J$ Virol 79: 8732-8741.

Schledzewski K, Brinkmann H, Mendel, RR. 1999. Phylogenetic analysis of components of the eukaryotic vesicle transport system reveals a common origin of adaptor protein complexes 1 , 2 , and 3 and the F subcomplex of the coatomer COPI. $J$ Mol Evol 48: 770-778.

Scott RJ, Cairo LV, Van de Vosse DW, Wozniak RW. 2009. The nuclear export factor Xpolp targets Mad1p to kinetochores in yeast. J Cell Biol 184: 21-29.

Seo HS, Ma Y, Debler EW, Wacker D, Kutik S, Blobel G, Hoelz A. 2009. Structural and functional analysis of Nup120 suggests ring formation of the Nup84 complex. Proc Natl Acad Sci 106: 14281-14286.

Shugrue CA, Kolen ER, Peters H, Czernik A, Kaiser C, Matovcik L, Hubbard AL, Gorelick F. 1999. Identification of the putative mammalian orthologue of Sec31P, a component of the COPII coat. J Cell Sci 112: 4547-4556.

Smith A, Brownawell A, Macara IG. 1998. Nuclear import of Ran is mediated by the transport factor NTF2. Curr Biol 8: 14031406.

Smith AE, Slepchenko BM, Schaff JC, Loew LM, Macara IG 2002. Systems analysis of Ran transport. Science 295: 488-491.

Stewart M. 2007a. Molecular mechanism of the nuclear protein import cycle. Nat Rev Mol Cell Biol 8: 195-208.

Stewart M. 2007b. Ratcheting mRNA out of the nucleus. Mol Cell 25: 327-330.

Stoffler D, Fega B, Fahrenkrog B, Walz J, Typke D, Aebi U. 2003. Cryo-electron tomography provides novel insights into nuclear pore architecture: Implications for nucleocytoplasmic transport. J Mol Biol 328: 119-130.

Strambio-de-Castillia C, Blobel G, Rout MP. 1999. Proteins connecting the nuclear pore complex with the nuclear interior. $J$ Cell Biol 144: 839-855.

Strambio-De-Castillia C, Niepel M, Rout MP. 2010. The nuclear pore complex: Bridging nuclear transport and gene regulation. Nat Rev Mol Cell Biol 11: 490-501.

Strawn LA, Shen T, Wente SR. 2001. The GLFG regions of Nup116p and Nup100p serve as binding sites for both Kap95p and Mex67p at the nuclear pore complex. J Biol Chem 276:
6445-6452.

Strawn L, Shen T, Shulga N, Goldfarb D, Wente S. 2004. Minimal nuclear pore complexes define FG repeat domains essential for transport. Nat Cell Biol 6: 197-206.

Suel KE, Gu H, Chook YM. 2008. Modular organization and combinatorial energetics of proline-tyrosine nuclear localization signals. PLoS Biol 6: e137.

Suntharalingam M, Wente SR. 2003. Peering through the pore: Nuclear pore complex structure, assembly, and function. Dev Cell 4: 775-789.

Taylor DJ, Thomas RK, Penfold J. 2007. Polymer/surfactant interactions at the air/water interface. Adv Colloid Interface Sci 132: 69-110.

ter Haar E, Musaccio A, Harrison SC, Kirchhausen T. 1998. Atomic structure of clathrin: A $\beta$ propeller terminal domain joins an $\alpha$ zigzag linker. Cell 95: 563-573.

Terry LJ, Wente SR. 2009. Flexible gates: Dynamic topologies and functions for FG nucleoporins in nucleocytoplasmic transport. Eukaryot Cell 8: 1814-1827.

Timney BL, Tetenbaum-Novatt J, Agate DS, Williams R, Zhang W, Chait BT, Rout MP. 2006. Simple kinetic relationships and nonspecific competition govern nuclear import rates in vivo. $J$ Cell Biol 175: 579-593.

Tran EJ, Wente SR. 2006. Dynamic nuclear pore complexes: Life on the edge. Cell 125: 1041-1053.

Tu LC, Musser SM. 2010. Single molecule studies of nucleocytoplasmic transport. Biochim Biophys Acta (in press).

Unwin PN, Milligan RA. 1982. A large particle associated with the perimeter of the nuclear pore complex. J Cell Biol 93: 6375.

Walther TC, Askjaer P, Gentzel M, Habermann A, Griffiths G, Wilm M, Mattaj IW, Hetzer M. 2003. RanGTP mediates nuclear pore complex assembly. Nature 424: 689-694.

Weirich CS, Erzberger JP, Berger JM, Weis K. 2004. The N-terminal domain of Nup159 forms a $\beta$-propeller that functions in mRNA export by tethering the helicase Dbp5 to the nuclear pore. Mol Cell 16: 749-760.

Wen W, Harootunian AT, Adams SR, Feramisco J, Tsien RY, Meinkoth JL, Taylor SS. 1994. Heat-stable inhibitors of cAMPdependent protein kinase carry a nuclear export signal. J Biol Chem 269: 32214-32220.

Wente SR. 2000. Gatekeepers of the nucleus. Science 288: 1374 1377.

Whittle JR, Schwartz TU. 2009. Architectural nucleoporins Nup157/ 170 and Nup133 are structurally related and descend from a second ancestral element. $J$ Biol Chem 284: 28442-28452.

Wickramasinghe VO, McMurtrie PI, Mills AD, Takei Y, PenrhynLowe S, Amagase Y, Main S, Marr J, Stewart M, Laskey RA. 2010. mRNA export from mammalian cell nuclei is dependent on GANP. Curr Biol 20: 25-31.

Yamada J, Phillips JL, Patel S, Goldfien G, Calestagne-Morelli A, Huang H, Reza R, Acheson J, Krishnan VV, Newsam S, et al. 2010. A bimodal distribution of two distinct categories of intrinsically-disordered structures with separate functions in FG nucleoporins. Mol Cell Proteomics 9: 2205-2224.

Yang Q, Rout MP, Akey CW. 1998. Three-dimensional architecture of the isolated yeast nuclear pore complex: Functional and evolutionary implications. Mol Cell 1: 223-234.

Yang W, Gelles J, Musser SM. 2004. Imaging of single-molecule translocation through nuclear pore complexes. Proc Natl Acad Sci 101: 12887-12892.

Yao W, Roser D, Köhler A, Bradatsch B, Bassler J, Hurt E. 2007. Nuclear export of ribosomal 60S subunits by the general mRNA export receptor Mex67-Mtr2. Mol Cell 26: 51-62.

Zeitler B, Weis K. 2004. The Ft-repeat asymmetry of the nuclear pore complex is dispensable for bulk nucleocytoplasmic transport in vivo. J Cell Biol 167: 583-590.

Zilman A. 2009. Effects of multiple occupancy and interparticle interactions on selective transport through narrow channels: Theory versus experiment. Biophys J 96: 1235-1248.

Zilman A, Di Talia S, Chait BT, Rout MP, Magnasco MO. 2007. Efficiency, selectivity, and robustness of nucleocytoplasmic transport. PLoS Comput Biol 3: e125. 
Zilman A, Di Talia S, Jovanovic-Talisman T, Chait BT, Rout MP, Magnasco MO. 2010. Enhancement of transport selectivity through nano-channels by non-specific competition. PLoS Comput Biol 6: e1000804.

Zimmerman SB, Minton AP. 1993. Macromolecular crowding:
Biochemical, biophysical, and physiological consequences. Annu Rev Biophys Biomol Struct 22: 27-65.

Zimmerman SB, Trach SO. 1991. Estimation of macromolecule concentrations and excluded volume effects for the cytoplasm of Escherichia coli. J Mol Biol 222: 599-620. 


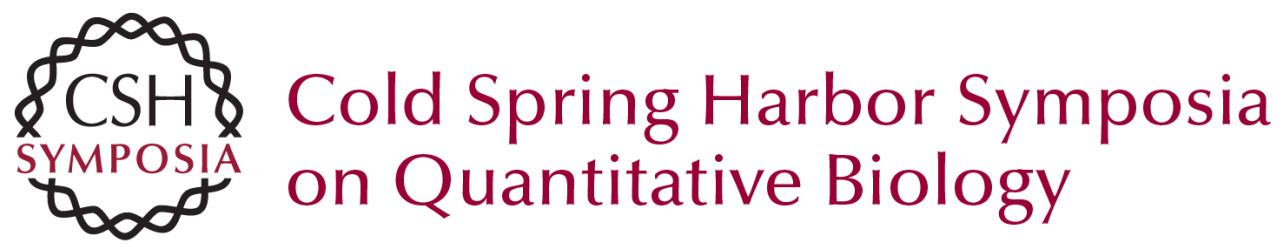

\section{The Mechanism of Nucleocytoplasmic Transport through the Nuclear Pore Complex}

J. Tetenbaum-Novatt and M.P. Rout

Cold Spring Harb Symp Quant Biol 2010 75: 567-584 originally published online March 29, 2011 Access the most recent version at doi:10.1101/sqb.2010.75.033

References This article cites 234 articles, 103 of which can be accessed free at: http://symposium.cshlp.org/content/75/567.full.html\#ref-list-1

\section{License}

Email Alerting Service top right corner of the article or click here.

To subscribe to Cold Spring Harbor Symposia on Quantitative Biology go to: http://symposium.cshlp.org/subscriptions 